\title{
Los desequilibrios económicos territoriales: el caso de la provincia de Cádiz
}

\author{
The territorial economic disparities: \\ the case of Cadiz province
}

\section{Antonio Rafael Peña Sánchez}

Facultad de Ciencias Sociales y de la Comunicación,

Campus de Jerez, Universidad de Cádiz, España rafael.pena@uca.es 


\title{
RESUMEN
}

El objetivo de este trabajo es poner de manifiesto cuál ha sido la evolución de las disparidades económicas territoriales en el interior de la provincia de Cádiz en el periodo 1991-2000, partiendo del hecho de que los distintos municipios han experimentado tasas de crecimiento desiguales en relación con el Valor Añadido Bruto y la población, que se han traducido en un comportamiento también diferenciado de las desigualdades en VAB por habitante. Por otro lado, analiza algunos factores explicativos de las disparidades económicas municipales en la provincia de Cádiz, tales como la aglomeración de población, la productividad y la estructura sectorial.

Palabras claves: disparidades económicas, desigualdades económicas, productividad del empleo, estructura sectorial.

Clasificación JEL: D31, O18, O47, R30.

\begin{abstract}
In this paper we intend to show which has been the evolution of the territorial economic disparities in the Cadiz province for the period 1991-2000, based on the fact that the different municipalities have experienced unequal rates of growth in relation to the Gross Value-Added and the population, which have been translated into a behaviour also differentiated from the inequalities in VAB per inhabitant. On the other hand, this paper analyzes some explanatory factors of the municipal economic disparities in the province of Cadiz, such as the agglomeration of population, the productivity and the sectorial structure.
\end{abstract}

Keywords: economic disparities, economic inequalities, productivity of employment, sectorial structure.

JEL Clasification: D31, O18, O47, R30.

Revista de Economía, vol. XXVII, núm. 74, primer semestre de 2010. 


\section{Introducción}

Las disparidades económicas en el interior de cualquier área geográfica pueden obstaculizar su crecimiento sostenido y equilibrado, dificultando la posible convergencia entre ésta y otras incluidas en un ámbito espacial superior (Richardson, 1975, 1977; Bueno Lastra, 1990). Desde esta perspectiva, la evidencia empírica sobre el proceso de crecimiento económico ha demostrado que la desigualdad en la distribución de la renta en el interior de un territorio reduce su crecimiento (Hirschman, 1958; Rupasingha et al., 2002); en este caso, cabe suponer que un eventual progreso en el estado del conocimiento sobre el crecimiento económico tendrá como recompensa la posibilidad de mejorar la efectividad de las políticas económicas, con el consiguiente efecto positivo en los niveles de vida de la sociedad (Rosende, 2000).

El desarrollo del Estado autonómico en España ha acelerado la necesidad de disponer de una fuente adecuada de información estadística que permita conocer la situación económica de las regiones españolas, su trayectoria y en qué medida ese proceso evolutivo conduce a la convergencia en los niveles promedio de desarrollo nacional. No se puede decir lo mismo en el ámbito de la estadística municipal, aunque también ha habido progresos significativos, sobre todo en los campos sociales y económicos. Sin embargo, la necesidad de información sobre la situación socioeconómica de los municipios no es menos importante, ya que sientan las bases para la planificación de acciones que permitan alcanzar un mayor nivel de desarrollo y bienestar entre sus ciudadanos.

Atendiendo al Valor Añadido Bruto per cápita (a partir de ahora VABpc) como indicador de desarrollo económico, la provincia de Cádiz ocupaba en 2002 la posición número 44 en el ranking de las provincias españolas, ${ }^{1}$ lo que, sin duda, pone de relieve la desfavorable situación de su estructura productiva. En este sentido, creemos oportuno realizar un análisis riguroso que permita detectar algunos elementos que puedan estar obstaculizando el potencial proceso de convergencia con el conjunto de provincias

\footnotetext{
${ }^{1}$ Dato tomado de la Contabilidad Regional de España, Base 1995 del Instituto Nacional de Estadística. Como podemos comprobar, la posición es muy desfavorable teniendo en cuenta que contamos con 50 provincias más Ceuta y Melilla.
} 
andaluzas y españolas. Por consiguiente, el objetivo del presente trabajo es, por un lado, poner de manifiesto cuál ha sido la evolución de las disparidades económicas territoriales en el interior de la provincia de Cádiz en el periodo 1991-200o partiendo del hecho de que los distintos municipios han experimentado tasas de crecimiento desiguales en relación con el Valor Añadido Bruto (VAB) y la población, que se ha traducido en un comportamiento también diferenciado de las desigualdades en VAB per cápita (VABpc); y, por otro lado, analizar algunos factores explicativos de las disparidades económicas municipales en la provincia de Cádiz, tales como la aglomeración de población, la productividad y la estructura sectorial. $^{2}$

La aportación de este trabajo se fundamenta en el análisis económico a nivel municipal que se realiza sobre la provincia gaditana en un periodo relativamente reciente y sobre el que existe aún muy poca información. Este examen trata de poner de manifiesto las diferencias municipales en la generación de producción, renta y empleo, influido por elementos como la productividad y la estructura sectorial, lo que sin duda va a condicionar el nivel de desarrollo de los ciudadanos de la provincia de Cádiz. Por consiguiente, este trabajo viene a complementar las escasas investigaciones que aún existen sobre un tema tan controvertido, por su carácter económico, político y social, como son las desigualdades económicas municipales en la provincia de Cádiz.

\section{Fuentes estadísticas consultadas}

Las fuentes estadísticas utilizadas han sido: a) la base de datos SIMA (Sistema de Información Multiterritorial de Andalucía) elaborado por el Instituto de Estadística de Andalucía (http://www.-juntadeandalucia.es/ iea/); b) la Renta Nacional de España y su distribución provincial, Serie homogénea, Años 1955 a 1993 y avances 1994 a 1997, de la Fundación BBV, y Años 1995 y avances 1996-1999 de la Fundación BBVA; c) la Contabilidad Regional de España, Base 1995, del Instituto Nacional de Estadística

\footnotetext{
${ }^{2}$ Por supuesto, éstos no son los únicos factores que influyen en la evolución del nivel de desarrollo y bienestar de la provincia. Pero dada la limitación de datos a nivel municipal, se ha creído conveniente centrar el análisis en estos elementos.
} 
(http://www.ine.es/); y d) los datos ofrecidos por el Servicio de Estudios de La Caixa (http://www.estudios.-lacaixa.comunicacions.com/).

\section{Rasgos diferenciales de la economía gaditana}

Aunque el objetivo de nuestro trabajo es poner de relieve el nivel y evolución de las disparidades económicas en el interior de la provincia gaditana, así como destacar algunos factores que explican dichas diferencias, hemos considerado necesario un examen previo de la evolución y situación del desarrollo económico (medido a partir del VABpc) de la provincia gaditana en el contexto regional y nacional, ya que el comportamiento de estos últimos han influido, sin duda, en la conducta de la provincia objeto de análisis.

La evaluación del desarrollo económico se ha centrado, inicialmente, en el comportamiento de tres macromagnitudes que cuantifican distintos vectores del crecimiento económico como son el Valor Añadido Bruto al coste de los factores (a partir de ahora VABcf), el empleo y la población.

Figura núm. 1

Participación del VABcf de la provincia de Cádiz en Andalucía y España

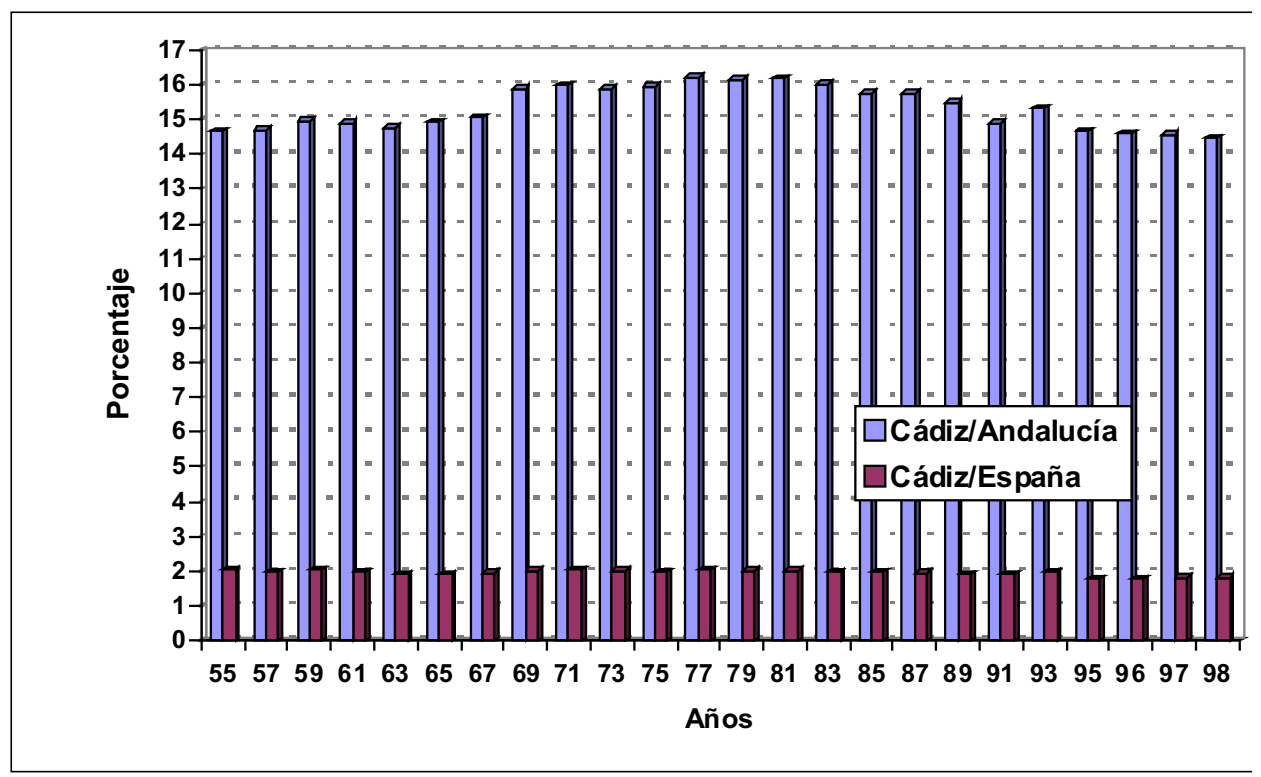

FUENTE: Elaboración propia a partir de los datos de la Fundación BBVA. 
Figura núm. 2

Participación del empleo de la provincia de Cádiz en Andalucía y España

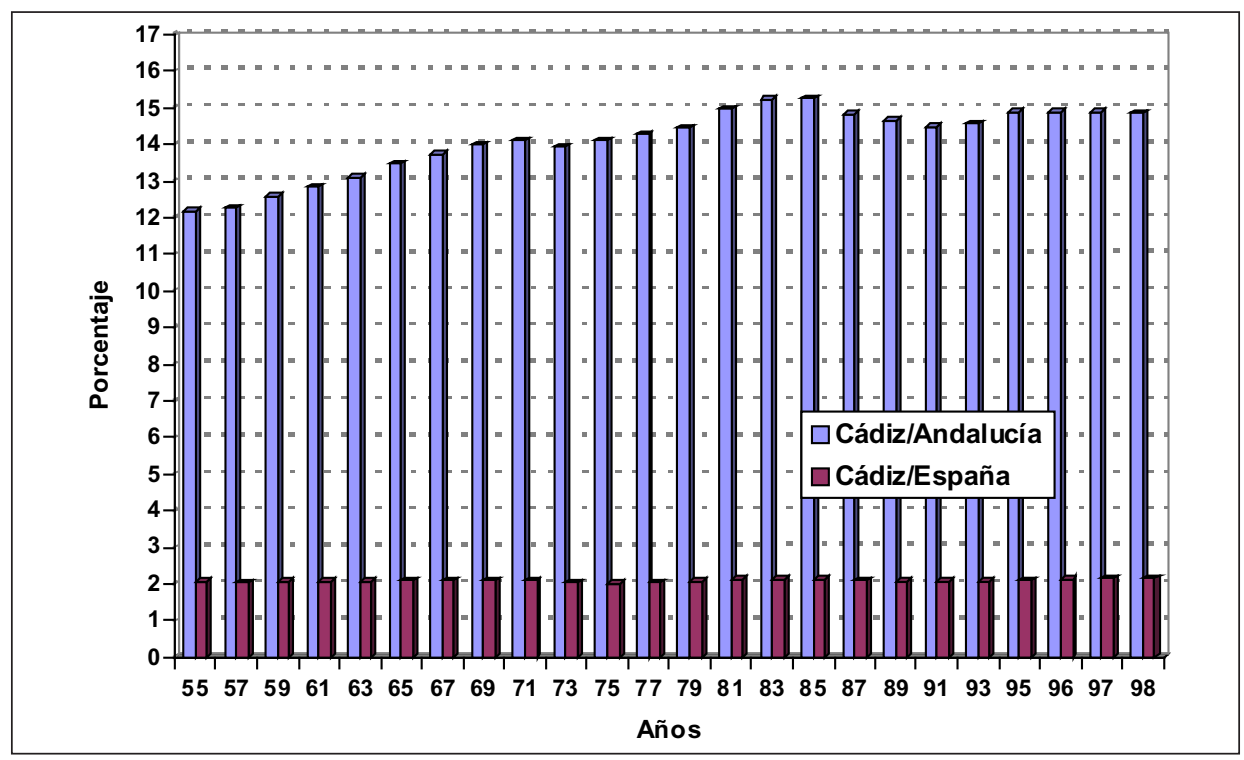

FUENTE: Elaboración propia a partir de los datos de la Fundación BBVA.

Figura núm. 3

Participación de la población de la provincia de Cádiz en Andalucía y España

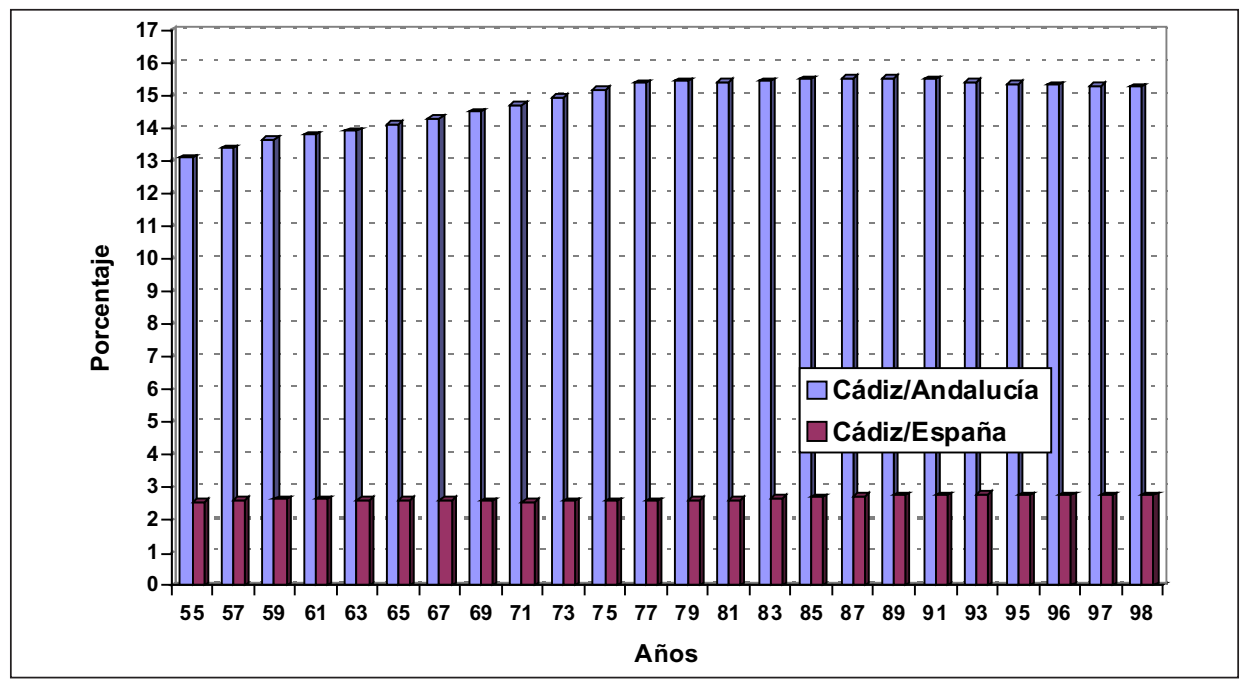

FUENTE: Elaboración propia a partir de los datos de la Fundación BBVA. 
Como puede observarse, en el periodo referido las variables han evolucionado de foma distinta. El peso del VABcf de la provincia de Cádiz ha experimentado un movimiento cíclico con respecto a Andalucía, aunque el peso con respecto a España ha ido descendiendo paulatinamente (figura núm. 1). Sin embargo, el peso del empleo con respecto a España se ha mantenido, mientras que con respecto a Andalucía ha experimentado una tendencia creciente, aunque también influida por los impulsos cíclicos de la economía española (figura núm. 2). Donde sí se observa una pauta evolutiva bien definida es en la población (figura núm. 3). El crecimiento demográfico en la provincia de Cádiz ha superado claramente al del conjunto regional y español, ganando peso en ambos, debido sobre todo al mayor crecimiento vegetativo, aunque parece que tiende a estabilizar su peso a partir de la década de los ochenta.

Conjugando los datos de VABcf y de población obtenemos los de VABpc, que en la figura núm. 4 se presentan indexados con relación a la media andaluza.

Figura núm. 4

Convergencia real en VABpc de Cádiz respecto a Andalucía

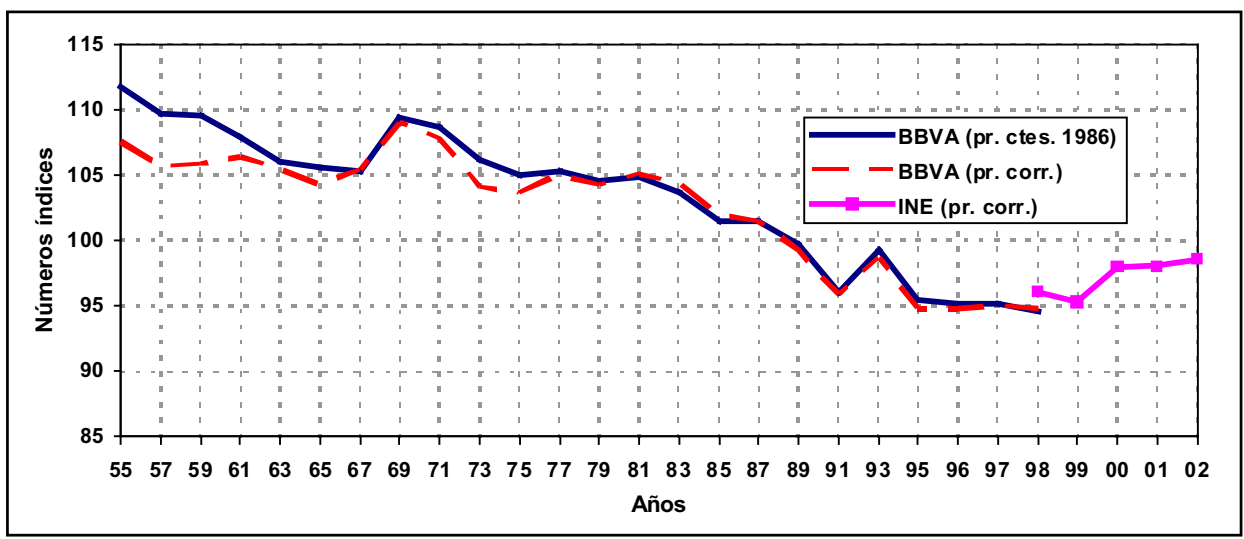

FUENTE: Elaboración propia a partir de los datos de la Fundación BBVA e INE.

Como era de prever, a la vista de la información anterior, la evolución de la convergencia real de Cádiz respecto al conjunto de las provincias andaluzas muestra una tendencia claramente descendente en el largo plazo, lo que implica una fuerte caída del desarrollo económico gaditano en su 
entorno regional. El índice de desarrollo económico, superior a la media regional en 1955, con un valor de 111,79, sufre un continuo descenso de su nivel hasta situarse en 1998 en 94,65, más de 5 puntos por debajo del nivel medio andaluz. No obstante, teniendo en cuenta los datos más recientes que nos proporciona la Contabilidad Regional de España (INE), en los últimos años ha experimentado un leve crecimiento, ya que el índice pasó de 96,11 en 1998 a 98,61 en 2002.

Figura Núm. 5

Convergencia real en VABpc de Cádiz respecto a España

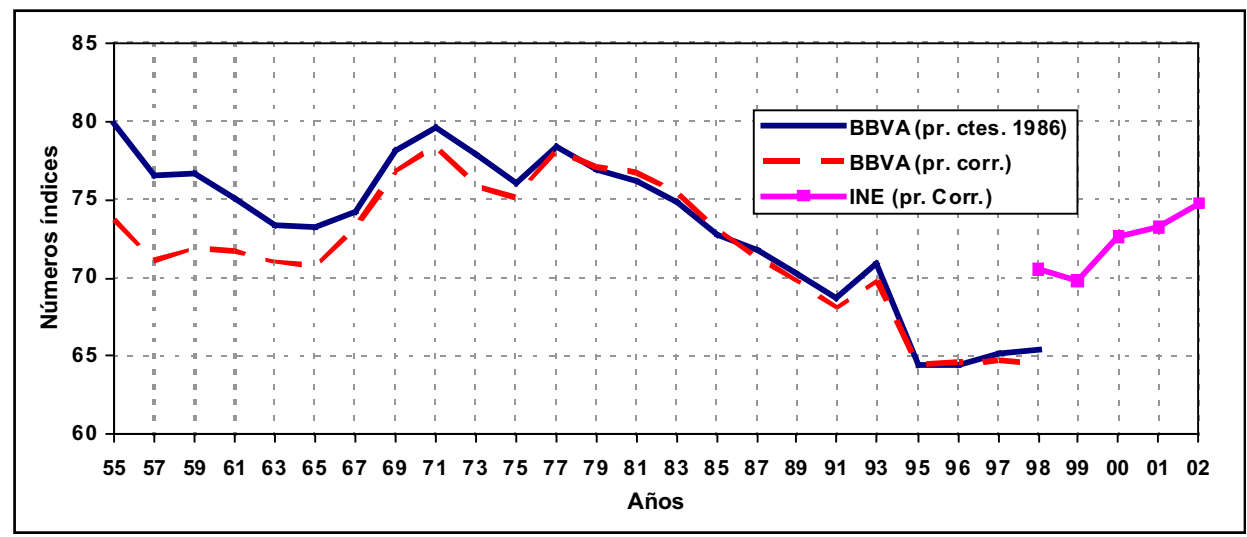

FUENTE: Elaboración propia a partir de los datos de la Fundación BBVA e INE.

Con respecto al conjunto de las provincias españolas, el proceso de convergencia muestra una dinámica similar a la descrita respecto a la media de Andalucía, pero con valores más reducidos. En este sentido, la figura núm. 5 pone de manifiesto la evolución descendente del nivel de desarrollo económico experimentado por la provincia de Cádiz que, según los datos de la Fundación BBVA, de contar con un índice de 79,79 en 1955, en el año 1998 el indicador era tan sólo de 65,39. Los datos ofrecidos por el INE muestran en los últimos años una tendencia convergente, presentando un crecimiento del nivel de desarrollo económico de más de 4 puntos (el índice pasó de 70,54 en 1998 a situarse en 74,73 en el año 2002).

Una vez puesto de manifiesto el desfavorable proceso de convergencia real en VABpc de la provincia de Cádiz en el escenario regional y español, aunque con síntomas de recuperación en los últimos años, y teniendo en 
cuenta que el VABpc conjuga los datos de VAB y población, se tratará de explicar a continuación la evolución negativa del nivel de desarrollo económico gaditano a partir del comportamiento de estas dos variables. Según los datos de la Fundación BBVA, la tasa de crecimiento anual acumulativo del VAB de la provincia de Cádiz en el periodo 1955-1998 fue de 3,60\%, inferior a la experimentada por Andalucía $(3,63 \%)$ y España $(3,89 \%)$ en el mismo periodo. A lo anterior podemos añadir que, refiriéndonos al mismo horizonte temporal, la población de la provincia de Cádiz experimentó un crecimiento anual acumulativo de 0,91\%, superior al de Andalucía (o,55\%) $\mathrm{y}$ al de España (o,73\%). Consecuentemente, la mayor intensidad en el aumento de población es la que ha imposibilitado una convergencia real positiva de la provincia de Cádiz. ${ }^{3}$ Ello ha provocado que el crecimiento anual acumulativo del VABpc en Cádiz, aún a pesar de ser positivo a lo largo del periodo analizado $(2,67 \%)$, haya sido bastante inferior al presentado por el conjunto de provincias andaluzas $(3,06 \%)$ y españolas $(3,14 \%)$.

Sin embargo, al referirnos al último periodo analizado 1998-2002, según los datos del INE, se observa un proceso de acercamiento de la provincia gaditana a su entorno regional y nacional, con un crecimiento de $6,19 \%$ frente a $6,24 \%$ de la andaluza y a 5,74\% de la española. La dinámica anterior fue debida, fundamentalmente, al crecimiento anual acumulativo del VAB de la provincia de Cádiz (6,74\%), algo inferior al de Andalucía $(6,83 \%)$ y superior al del conjunto de provincias españolas (6,69\%), y al menor crecimiento experimentado por la población en el mismo periodo (o,52\% frente a $0,55 \%$ de Andalucía y o,89\% en España).

Cuadro núm. 1

Estructura sectorial año 2002 (En \% sobre total)

\begin{tabular}{|l|cccc|rccc|}
\hline & \multicolumn{4}{|c|}{ VAB } & \multicolumn{4}{c|}{ Población ocupada } \\
& Agric. & Indust. & Construc. & Servic. & Agric. & Indust. & Construc. & Servic. \\
\hline Cádiz & 4,75 & 18,50 & 11,57 & 65,18 & 6,98 & 10,67 & 15,52 & 66,84 \\
Andalucía & 6,67 & 12,99 & 11,04 & 69,29 & 10,45 & 11,71 & 13,58 & 64,27 \\
España & 3,37 & 20,11 & 9,60 & 66,92 & 5,91 & 19,40 & 11,77 & 62,92 \\
\hline
\end{tabular}

FUENTE: Elaboración propia a partir de los datos del IEA.

\footnotetext{
${ }^{3}$ De hecho, el peso de la población de Cádiz con respecto a Andalucía y a España ha supuesto en el año 2002 el 15,25\% de la población total andaluza y el 2,73\% total de la población española, con tan sólo el 8,46\% del territorio andaluz y el 1,46\% del territorio nacional.
} 
Como rasgo también diferencial de la economía gaditana, la estructura sectorial comparativa nos indica, por un lado, el mayor peso de la agricultura como actividad productiva respecto a España y el menor porcentaje con respecto a Andalucía y, por otro lado, la mayor proporción de la industria con respecto a Andalucía (cuadro núm. 1). No obstante, el sector servicios es destacable en los tres escenarios analizados, ya que en cualquier caso es superior al 60\% del total de la actividad productiva, propio del proceso de terciarización experimentado desde hace varias décadas por la economía española en general, y la andaluza y gaditana en particular.

Cuadro núm. 2

Productividad sectorial año 2002

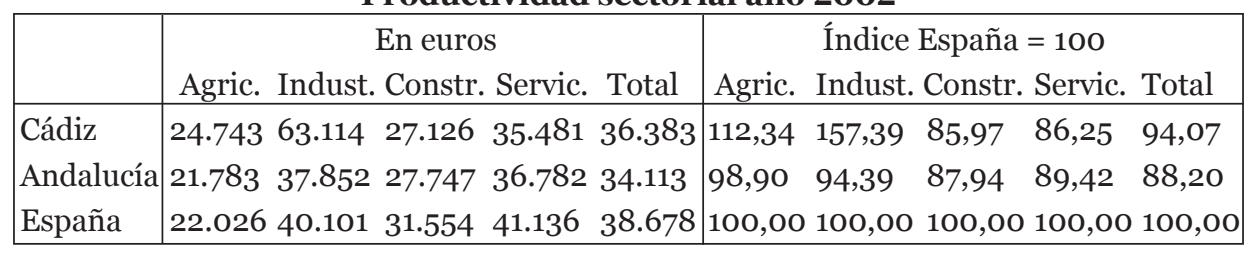

FUENTE: Elaboración propia a partir de los datos del IEA.

Con referencia a la productividad total y sectorial, se observa cómo la productividad gaditana (36.383 euros) es superior a la andaluza (34.113 euros) pero inferior a la española (38.678 euros). La razón no es otra que la mayor productividad de los sectores agrario (24.743 frente a 21.783 euros de Andalucía y 22.026 euros en España) y, sobre todo, la industrial (63.114 frente a 37.852 y 40.101, respectivamente), este último dato muy superior al dato tanto regional como nacional.

Por consiguiente, la provincia de Cádiz se caracteriza por tener, de forma análoga a su entorno regional y nacional, una estructura productiva basada fundamentalmente en el sector servicios, aunque su productividad es inferior a la media regional y nacional. Además, cuenta con un sector agrario con mayor dimensión que la media nacional y con una alta productividad, aunque muy sometido a factores climáticos poco controlables y con una alta concentración en las explotaciones agrarias (Peña Sánchez y Rodríguez García, 1996a y 1996b), ${ }^{4}$ y un destacado sector industrial

${ }^{4}$ Factor este último, de la desigual estructura de la propiedad agraria, que ha condicionado en muchos aspectos el desarrollo económico de la región andaluza en general y de la 
respecto al entorno regional y algo inferior al entorno nacional, aunque con una productividad muy superior.

\section{Análisis municipal de las disparidades económicas en la pro- vincia de Cádiz}

Teniendo en cuenta la carencia de datos municipales de VAB y renta por parte de las fuentes estadísticas disponibles, para el análisis de las disparidades económicas en el interior de la provincia de Cádiz se ha establecido un indicador de estimación indirecto del VAB agrupando un conjunto de variables muy influyentes en el mismo de las que se dispone de cifras a nivel municipal para el periodo 1991-2000: $:^{5}$ consumo de energía eléctrica, IRPF rentas declaradas, líneas telefónicas en servicio, número de actividades empresariales según el Impuesto de Actividades Económicas y parque global de vehículos. Con estas variables se ha aplicado la siguiente expresión:

$$
I V A B=\sqrt[n]{\prod_{i=1}^{n} x_{i}^{w_{i}}}
$$

siendo $I V A B$ el indicador del VAB o indicador de renta; $x_{i}$ el valor que adopta cada una de las variables consideradas; $w_{i}$ las ponderaciones para cada una de las variables utilizadas ${ }^{6}$ y $n$ el número de variables consideradas.

provincia de Cádiz en particular. (Véase al respecto Delgado Cabeza, 2001.) En este sentido, Delgado Cabeza y González de Molina (2001) se pronuncian cuando concluyen en su trabajo: "la centralización del excedente (refiriéndose al agrario), asociada a una desigual estructura de la propiedad de la tierra, que ha sido un elemento clave en el planteamiento de la cuestión agraria en el campo andaluz, continúa presente en un proceso que conlleva un progresivo distanciamiento entre población y recursos". Del mismo modo, Cuadrado Roura (Dir.) et al. (1983) exponen que "la distribución de la tierra en explotaciones presenta un fuerte desequilibrio y concentración; es una de las provincias españolas (refiriéndose a la provincia de Cádiz) con mayor grado de latifundio ...”.

${ }^{5}$ Este indicador sintético de VAB fue aplicado en Peña Sánchez (2006 y 2007) para el caso de las comarcas andaluzas. Algunos trabajos que utilizan métodos similares para el cálculo de indicadores económicos son, entre otros, Alonso y Freire-Serén (2002), Almeida García y Granados Cabezas (1999), Cancelo de la Torre y Uriz Tomé (1994), Draper y Herce (1994).

${ }^{6}$ Las ponderaciones han sido tomadas de los coeficientes de correlación lineal simple de la renta con cada uno de los indicadores utilizados con datos correspondientes a las 50 
Como toda estimación basada en métodos indirectos, los resultados obtenidos deben tomarse con las debidas precauciones, ya que se trata de una metodología que sólo depara cuantificaciones aproximadas y que, básicamente, adquiere una mayor relevancia en la posible comparación interterritorial en la provincia de Cádiz.

La obtención del indicador a nivel municipal de VAB y la serie de datos con la que contamos de población nos permite ofrecer un indicador de VAB per cápita en la tabla que se adjunta a continuación (en números índices), así como la tasa de crecimiento medio anual acumulado para el periodo 1991-2000 y la diferencia de ésta con la tasa media de la provincia (cuadro núm. 3).

Cuadro Núm. 3

Variación en el VAB per cápita por municipios (1991-200o)

\begin{tabular}{|lrrrcc|}
\hline & NI (Provincia Cádiz $=100$ & & TVMAA & Variación s/ \\
& 1991 & 2000 & Diferencia & $1991-2000$ & tasa gaditana \\
\hline Alcalá de los Gazules & 53,55 & 66,51 & 12,96 & 6,09 & 2,53 \\
Alcalá del Valle & 38,02 & 53,41 & 15,39 & 7,55 & 3,99 \\
Algar & 61,99 & 73,70 & 11,71 & 5,57 & 2,01 \\
Algeciras & 111,77 & 106,44 & $-5,33$ & 3,00 & $-0,56$ \\
Algodonales & 44,05 & 58,93 & 14,88 & 6,97 & 3,41 \\
Arcos de la Frontera & 65,29 & 73,57 & 8,28 & 4,95 & 1,39 \\
Barbate & 65,58 & 71,88 & 6,30 & 4,63 & 1,07 \\
Barrios (Los) & 197,91 & 224,31 & 26,40 & 5,02 & 1,46 \\
Benaocaz & 56,00 & 78,95 & 22,95 & 7,59 & 4,03 \\
Bornos & 53,26 & 64,11 & 10,85 & 5,72 & 2,16 \\
Bosque (El) & 75,73 & 83,73 & 8,00 & 4,73 & 1,17 \\
Cádiz & 115,81 & 98,64 & $-17,17$ & 1,73 & $-1,83$ \\
Castellar de la Frontera & 87,86 & 113,92 & 26,06 & 6,60 & 3,04 \\
\hline
\end{tabular}

continua cuadro...

provincias españolas tal y como realizan Clavero et al. (1988). Además, para ello estamos partiendo de la hipótesis de que la influencia de todos estos factores en la renta es la misma, tanto a nivel nacional, como a nivel de los municipios gaditanos. Lógicamente ésta es una hipótesis muy restrictiva, pero es inevitable dada la limitación de la información estadística disponible. Hemos de añadir también que todos los coeficientes de correlación simples toman valores superiores a 0,90. Asimismo, con el fin de evitar la restricción impuesta por la hipótesis anterior, se probó realizar dicho indicador sin las ponderaciones y los resultados obtenidos fueron muy similares. 


\begin{tabular}{|lrrrrr|}
\hline Conil de la Frontera & 67,84 & 87,76 & 19,92 & 6,57 & 3,01 \\
Chiclana de la Frontera & 83,84 & 100,68 & 16,84 & 5,69 & 2,13 \\
Chipiona & 79,03 & 88,78 & 9,75 & 4,91 & 1,35 \\
Espera & 43,61 & 55,76 & 12,15 & 6,43 & 2,87 \\
Gastor (El) & 46,31 & 60,61 & 14,30 & 6,71 & 3,15 \\
Grazalema & 59,03 & 75,63 & 16,60 & 6,46 & 2,90 \\
Jerez de la Frontera & 107,87 & 107,16 & $-0,71$ & 3,49 & - o,o7 \\
Jimena de la Frontera & 77,24 & 84,18 & 6,94 & 4,56 & 1,00 \\
Línea de la Concepción (La) & 81,58 & 79,99 & $-1,59$ & 3,34 & $-0,22$ \\
Medina-Sidonia & 55,93 & 71,02 & 15,09 & 6,35 & 2,79 \\
Olvera & 61,57 & 75,19 & 13,62 & 5,89 & 2,33 \\
Paterna de Rivera & 40,25 & 50,62 & 10,37 & 6,24 & 2,68 \\
Prado del Rey & 56,41 & 65,94 & 9,53 & 5,38 & 1,82 \\
Puerto de Santa María (El) & 119,23 & 113,28 & $-5,95$ & 2,98 & $-0,58$ \\
Puerto Real & 125,19 & 125,21 & 0,02 & 3,57 & 0,01 \\
Puerto Serrano & 31,18 & 51,52 & 20,34 & 9,51 & 5,95 \\
Rota & 171,77 & 158,37 & $-13,40$ & 2,63 & $-0,93$ \\
San Fernando & 96,29 & 87,50 & $-8,79$ & 2,47 & $-1,09$ \\
Sanlúcar de Barrameda & 107,64 & 76,72 & $-30,92$ & $-0,26$ & $-3,82$ \\
San Roque & 138,99 & 230,12 & 91,13 & 9,53 & 5,97 \\
Setenil de las Bodegas & 49,55 & 65,26 & 15,71 & 6,78 & 3,22 \\
Tarifa & 73,53 & 86,27 & 12,74 & 5,42 & 1,86 \\
Torre Alháquime & 43,30 & 63,43 & 20,13 & 8,05 & 4,49 \\
Trebujena & 53,35 & 68,61 & 15,26 & 6,50 & 2,94 \\
Ubrique & 71,12 & 72,58 & 1,46 & 3,80 & 0,24 \\
Vejer de la Frontera & 65,72 & 76,09 & 10,37 & 5,26 & 1,70 \\
Villaluenga del Rosario & 37,45 & 54,53 & 17,08 & 7,98 & 4,42 \\
Villamartín & 56,75 & 73,08 & 16,33 & 6,52 & 2,96 \\
Zahara de la Sierra & 46,36 & 68,29 & 21,93 & 8,12 & 4,56 \\
Benalup-Casas Viejas & $\mathrm{n} . \mathrm{d}$. & 66,30 & $\mathrm{n} . \mathrm{d}$. & $\mathrm{n} . \mathrm{d}$. & $\mathrm{n} . \mathrm{d}$. \\
San José del Valle & $\mathrm{n} . \mathrm{d}$. & 83,89 & $\mathrm{n} . \mathrm{d}$. & $\mathrm{n} . \mathrm{d}$. & $\mathrm{n} . \mathrm{d}$. \\
Total provincias de Cádiz & 100,00 & 100,00 & 0,00 & 3,56 & 0,00 \\
\hline
\end{tabular}

FUENTE: Elaboración propia a partir de los datos del IEA. 
Antonio Rafael Peña Sánchez

Figura no 6

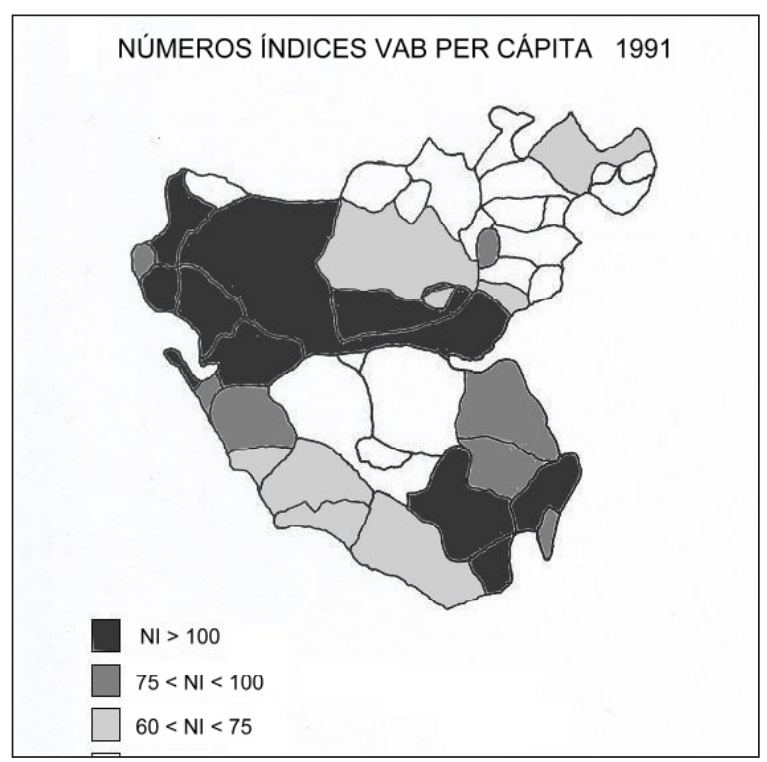

FUENTE: Elaboración propia.

Figura $\mathbf{n}^{\mathbf{0}} 7$

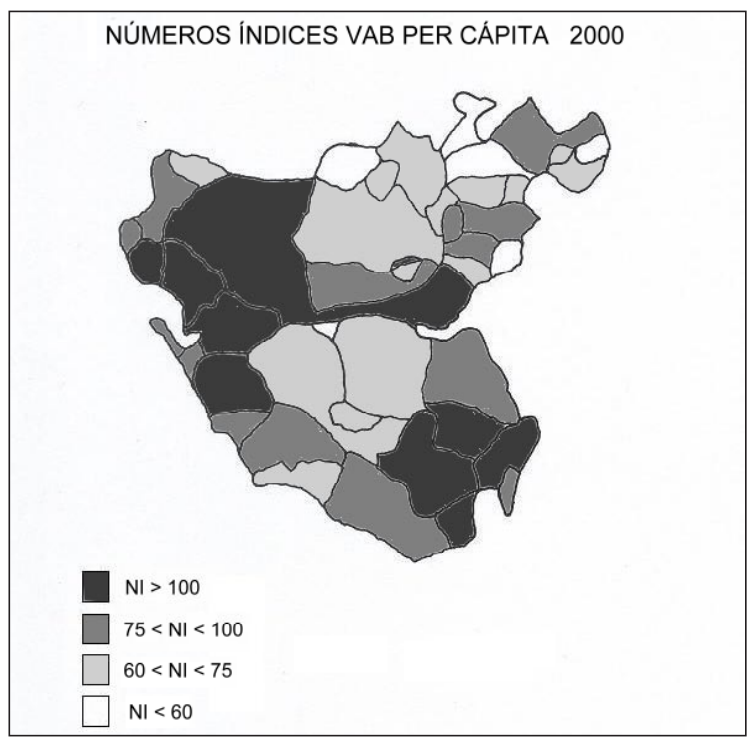

FUENTE: Elaboración propia. 
Los cuadros y mapas presentados (figuras núms. 6 y 7) muestran de forma visible las fuertes disparidades existentes entre los municipios gaditanos en VABpc tanto en el año 1991 como en el 2000. ${ }^{7}$ Por un lado se encuentran municipios con un alto índice de VABpc en el periodo analizado, como son Algeciras, Cádiz, Jerez de la Frontera, El Puerto de Santa María, Puerto Real, Rota y San Roque (todos ellos municipios costeros excepto Jerez de la Frontera) y por otro, municipios con un bajo índice de VABpc como Alcalá del Valle, Algodonales, Espera, El Gastor, Paterna de Rivera, Puerto Serrano, Setenil de las Bodegas, Torre Alháquime, Villaluenga del Rosario y Zahara de la Sierra (todos municipios de la Sierra excepto Paterna de Rivera, municipio de la Janda). La dualidad económica que presenta la provincia, por tanto, es manifiesta. La zona costera, que comprende los municipios con mayor grado de prosperidad económica, y los municipios de la Sierra, más deprimidos económicamente.

Ahora bien, la mayoría de los municipios gaditanos experimentan crecimientos en el índice de VABpc en el periodo analizado. La excepción a este comportamiento positivo se muestra en los municipios de Algeciras, Cádiz, Jerez de la Frontera, La línea de la Concepción, El Puerto de Santa María, Rota, San Fernando y Sanlúcar de Barrameda, cuyos crecimientos anuales acumulados han sido inferiores al crecimiento medio provincial. Adicionalmente, es necesario resaltar que todos estos municipios, con excepción de La Línea de la Concepción y San Fernando, contaban con un VABpc superior a la media provincial en 1991.

${ }^{7}$ Véase el anexo I de este trabajo. 
Antonio Rafael Peña Sánchez

Cuadro núm. 4

Peso y crecimiento anual acumulativo (1991-2000) de los municipios gaditanos en VAB y población (En \%)

\begin{tabular}{|c|c|c|c|c|c|c|c|c|c|}
\hline & \multirow[b]{2}{*}{ Superf. } & \multicolumn{4}{|c|}{ VAB } & \multicolumn{4}{|c|}{ POBLACIÓN } \\
\hline & & 1991 & 2000 & Var. & TCM & 1991 & 2000 & Var. & TCM \\
\hline Alcalá de los Gazules & 6,44 & 0,28 & 0,33 & 0,05 & 6,02 & 0,52 & 0,49 & $-0,03$ & $-0,07$ \\
\hline Alcalá del Valle & 0,63 & 0,19 & 0,25 & 0,06 & 7,45 & 0,49 & 0,47 & $-0,02$ & $-0,09$ \\
\hline Algar & 0,36 & 0,11 & 0,12 & 0,01 & 5,02 & 0,17 & 0,16 & $-0,01$ & $-0,52$ \\
\hline Algeciras & 1,16 & 10,49 & 9,85 & $-0,65$ & 3,32 & 9,39 & 9,25 & $-0,14$ & 0,31 \\
\hline Algodonales & 1,81 & 0,23 & 0,29 & 0,06 & 6,69 & 0,53 & 0,50 & $-0,03$ & $-0,26$ \\
\hline Arcos de la Frontera & 7,09 & 1,63 & 1,83 & 0,20 & 5,39 & 2,50 & 2,49 & $-0,01$ & 0,42 \\
\hline Barbate & 1,91 & 1,32 & 1,41 & 0,09 & 4,83 & 2,01 & 1,96 & $-0,05$ & 0,19 \\
\hline Barrios (Los) & 4,46 & 2,51 & 3,35 & 0,85 & 7,47 & 1,27 & 1,50 & 0,23 & 2,34 \\
\hline Benaocaz & 0,94 & 0,03 & 0,05 & $\mathrm{O}, 02$ & 10,28 & 0,05 & 0,06 & 0,01 & 2,49 \\
\hline Bornos & 0,74 & 0,39 & 0,45 & 0,06 & 5,77 & 0,73 & 0,70 & $-0,03$ & 0,04 \\
\hline Bosque (El) & 0,42 & 0,12 & 0,14 & 0,01 & 5,35 & 0,16 & 0,17 & $\mathrm{O}, \mathrm{OO}$ & 0,60 \\
\hline Cádiz & 0,16 & 16,58 & 12,28 & $-4,30$ & 0,64 & 14,31 & 12,45 & $-1,86$ & $-1,07$ \\
\hline Castellar de la Frontera & 2,40 & 0,18 & 0,26 & 0,07 & 7,90 & 0,21 & 0,22 & 0,01 & 1,22 \\
\hline Conil de la Frontera & 1,17 & 0,98 & 1,39 & 0,41 & 8,14 & 1,44 & 1,58 & 0,13 & 1,47 \\
\hline Chiclana de la Frontera & 2,78 & 3,64 & 5,36 & 1,71 & 8,61 & 4,35 & 5,32 & 0,97 & 2,76 \\
\hline Chipiona & 0,44 & 1,05 & 1,31 & 0,26 & 6,62 & 1,33 & 1,47 & 0,14 & 1,63 \\
\hline Espera & 1,65 & 0,17 & 0,20 & 0,03 & 6,02 & 0,38 & 0,35 & $-0,03$ & $-0,39$ \\
\hline Gastor (El) & 0,38 & 0,09 & 0,11 & 0,01 & 5,58 & 0,20 & 0,17 & $-0,03$ & $-1,05$ \\
\hline Grazalema & 1,63 & 0,12 & 0,15 & 0,03 & 6,46 & 0,21 & 0,20 & $-0,01$ & 0,00 \\
\hline Jerez de la Frontera & 15,93 & 18,34 & 17,49 & $-0,84$ & 3,51 & 17,00 & 16,33 & $-0,67$ & $\mathrm{O}, \mathrm{O} 2$ \\
\hline Jimena de la Frontera & 4,66 & 0,63 & 0,68 & 0,05 & 4,88 & 0,82 & 0,81 & $-0,01$ & 0,31 \\
\hline Línea de la Concepción (La) & 0,35 & 4,41 & 4,27 & $-0,15$ & 3,66 & 5,41 & 5,33 & $-0,08$ & 0,32 \\
\hline Medina-Sidonia & 6,62 & 0,85 & 0,68 & $-0,16$ & 1,58 & 1,51 & 0,96 & $-0,55$ & $-4,48$ \\
\hline Olvera & 2,61 & 0,52 & 0,58 & 0,06 & 5,35 & 0,84 & 0,77 & $-0,07$ & $-0,51$ \\
\hline Paterna de Rivera & 0,19 & 0,18 & 0,23 & 0,05 & 6,96 & 0,45 & 0,46 & 0,01 & 0,68 \\
\hline Prado del Rey & 0,66 & 0,29 & 0,34 & 0,05 & 6,03 & 0,51 & 0,52 & 0,01 & 0,62 \\
\hline Puerto de Santa María (El) & 2,14 & 7,24 & 7,60 & 0,36 & 4,61 & 6,08 & 6,71 & 0,63 & 1,59 \\
\hline Puerto Real & 2,65 & 3,44 & 3,92 & 0,47 & 5,56 & 2,75 & 3,13 & 0,38 & 1,92 \\
\hline Puerto Serrano & 1,07 & 0,19 & 0,31 & 0,12 & 10,02 & 0,60 & 0,60 & 0,00 & 0,47 \\
\hline Rota & 1,13 & 3,61 & 3,60 & $-0,02$ & 4,00 & 2,10 & 2,27 & 0,17 & 1,33 \\
\hline San Fernando & 0,43 & 7,63 & 6,86 & $-0,77$ & 2,83 & 7,92 & 7,84 & $-0,08$ & 0,36 \\
\hline Sanlúcar de Barrameda & 2,34 & 5,59 & 4,23 & $-1,37$ & 0,87 & 5,19 & 5,51 & 0,31 & 1,13 \\
\hline San Roque & 1,88 & 2,74 & 4,70 & 1,97 & 10,51 & 1,97 & 2,04 & 0,08 & 0,89 \\
\hline Setenil de las Bodegas & 1,10 & 0,15 & 0,18 & 0,03 & 6,30 & 0,30 & 0,27 & $-0,02$ & $-0,45$ \\
\hline Tarifa & 5,63 & 0,99 & 1,19 & 0,20 & 6,18 & 1,35 & 1,38 & O,03 & 0,72 \\
\hline Torre Alháquime & 0,24 & 0,04 & 0,05 & 0,01 & 6,93 & 0,09 & 0,08 & $-0,01$ & $-1,04$ \\
\hline Trebujena & 0,93 & 0,35 & 0,42 & 0,08 & 6,42 & 0,65 & 0,62 & $-0,03$ & $-0,07$ \\
\hline Ubrique & 0,95 & 1,19 & 1,13 & $-0,06$ & 3,50 & 1,67 & 1,56 & $-0,11$ & $-0,29$ \\
\hline Vejer de la Frontera & 3,55 & 0,78 & 0,86 & 0,08 & 5,16 & 1,19 & 1,13 & $-0,06$ & $-0,10$ \\
\hline Villaluenga del Rosario & 0,77 & $\mathrm{O}, 02$ & 0,02 & $\mathrm{O}, \mathrm{OO}$ & 6,15 & 0,05 & 0,04 & $-0,01$ & $-1,69$ \\
\hline Villamartín & 2,82 & 0,65 & 0,78 & 0,13 & 6,11 & 1,15 & 1,06 & $-0,08$ & $-0,38$ \\
\hline Zahara & 0,97 & 0,07 & 0,09 & 0,03 & 7,74 & 0,15 & 0,14 & $-0,01$ & $-0,35$ \\
\hline Benalup-Casas Viejas & 0,78 & n.d. & 0,37 & 0,37 & n.d. & n.d. & 0,56 & 0,56 & n.d. \\
\hline San José del Valle & 3,04 & n.d. & 0,32 & 0,32 & n.d. & n.d. & 0,38 & 0,38 & n.d. \\
\hline Total provincias de Cádiz & 100,00 & 100,00 & 100,00 & & 4,05 & 100,00 & 100,00 & & 0,47 \\
\hline
\end{tabular}

FUENTE: Elaboración propia a partir de los datos del IEA. 
El análisis de los cambios experimentados por los municipios gaditanos en el índice de VABpc a partir de su descomposición en VAB y población (cuadro núm. 4) permite aportar algunas reflexiones al estudio que se viene realizando:

$\left.1^{0}\right)$ La configuración de los grandes centros de actividad económica de la provincia de Cádiz viene determinada por los municipios de Algeciras, Cádiz, Chiclana, Jerez de la Frontera, La Línea de la Concepción, El Puerto de Santa María, Puerto Real, Rota, San Fernando y Sanlúcar de Barrameda. Su fuerte peso productivo (aunque descendió de 80,97\% a 75,46\% en el periodo analizado) y poblacional (cuyo peso disminuyó ligeramente de 74,50\% a 74,14\%) se encuentra concentrado en tan sólo 29,06\% del territorio. Cabe destacar también los municipios de Chiclana de la Frontera y San Roque por el relevante aumento experimentado en la proporción del $\mathrm{VAB}$ en el periodo considerado, que pasó de 6,38\% en 1991 a 10,06\% en el año 2000, y el fuerte ascenso demográfico, pasando de $6,32 \%$ a $7,36 \%$ en el mismo periodo, con tan sólo 4,66\% del territorio.

$2^{\circ}$ ) El fuerte peso económico del litoral gaditano frente al conjunto de municipios de la provincia. En este sentido, los municipios del litoral gaditano, con $27,7 \%$ de la superficie total, contaban en 1991 con $70,53 \%$ de la producción y $66,79 \%$ de la población total de la provincia, mientras que en el año 2000 el peso productivo pasó a 68,83\% y el peso demográfico a $67,37 \%$. Así pues, se puede deducir que dichos municipios, que no dejan de ser por lo general los más prósperos de la provincia, han perdido peso productivo (concretamente en 1,7 puntos) y han concentrado algo más de población ( 0,58 puntos).

$3^{\circ}$ ) La razón de la disminución en el índice de VABpc de los municipios más prósperos anteriormente mencionados ha sido la siguiente: En el caso de Algeciras, Cádiz, La Línea de la Concepción, San Fernando y Sanlúcar de Barrameda, la destacada disminución del peso en VAB que ha originado un relevante descenso en el indicador de VABpc, mientras que en el caso de El Puerto de Santa María y Rota es el peso de la población la que ha aumentado, haciendo disminuir el índice de VABpc.

$4^{\circ}$ ) Sin profundizar en aspectos causales, ${ }^{8}$ por lo general el crecimiento de población, y por tanto, el grado de concentración demográfica, ha

\footnotetext{
${ }^{8}$ Ya que, como hemos podido comprobar, una posible causa de los distintos niveles de producción per cápita pueden ser los volúmenes de población que albergan, pero también
} 
sido mayor en aquellos municipios que partían con un mayor nivel de desarrollo económico (VABpc) en 1991, y que, por tanto, cuentan, presumiblemente, con mayores oportunidades en el mercado laboral. En este sentido, la relación anterior, junto con el desglose del crecimiento de la población, viene expresada en el siguiente cuadro.

\begin{tabular}{|c|c|c|c|}
\hline \multicolumn{4}{|c|}{$\begin{array}{c}\text { Cuadro núm. } 5 \\
\text { Relación del crecimiento de la población (1991-200o) con el nivel de VAB } \\
\text { per cápita del año } 1991\end{array}$} \\
\hline $\begin{array}{l}\text { Variable dependiente } \\
\text { MCO } \\
\text { Estimaciones }\end{array}$ & Cto. Población & Cto. Veget. & Saldos Migr. \\
\hline Constante & $-0,941592\left(^{* * *}\right)$ & $0,175321(*)$ & $-0,522215\left(^{(* *}\right)$ \\
\hline NI VAB per cápita 1991 & $0,015928(* * *)$ & $0,003146(* *)$ & $0,006294(* *)$ \\
\hline $\mathrm{R} 2$ & 0,217056 & 0,184217 & 0,119781 \\
\hline R2 Ajustado & 0,197483 & 0,163823 & 0,097776 \\
\hline Test de White (n R2) & 0,377123 & 1,779233 & 0,379426 \\
\hline $\mathrm{F}$ & 11,08923 & 9,03267 & 5,443236 \\
\hline $\mathrm{n}$ & 42 & 42 & 42 \\
\hline \multicolumn{4}{|c|}{$\begin{array}{r}\text { NOTA: }(*) \text { Significativo a un nivel de confianza de } 90 \% . \\
(* *) \text { Significativo a un nivel de confianza de } 95 \% . \\
(* *) \text { Significativo a un nivel de confianza de } 99 \% .\end{array}$} \\
\hline
\end{tabular}

FUENTE: Elaboración propia.

Los resultados del cuadro núm. 5 muestran cómo tanto el crecimiento vegetativo como los saldos migratorios en el periodo analizado han venido influido por el nivel de VABpc existente en los municipios gaditanos en el año 1991. No obstante, es necesario resaltar que la mayor parte de los municipios gaditanos han presentado saldos migratorios negativos, destacando por su importancia Cádiz (-18.211 personas) y Jerez de la Frontera (-6.419 personas), debido quizás al menor nivel de desarrollo que presentaban el conjunto de las comarcas de dicha provincia en 1991 $(96,41)$, tomando valor 100 el conjunto de comarcas andaluzas, ${ }^{9}$ lo que ha

es cierto que la literatura económica sobre el desarrollo económico considera la aglomeración de población como un factor que favorece el nivel de desarrollo económico que presentan los distintos territorios.

${ }^{9}$ Dicho valor ha sido tomado de Peña Sánchez (2006). Los datos obtenidos para el resto de las provincias andaluzas según el indicador utilizado en dicho trabajo fueron los siguientes: Almería 98,61; Córdoba 95,62; Granada 92,06; Huelva 108,08; Jaén 90,80; Málaga 107,42; y Sevilla 104,78. 
originado una emigración neta de 14.653 personas hacia otros territorios andaluces y no andaluces más prósperos y con mayores oportunidades de empleo. Por el contrario, con saldos migratorios positivos nos encontramos Chiclana de la Frontera (9.676 personas), Puerto Real (3.167 personas) y El Puerto de Santa María (2.880 personas). Ahora bien, los saldos migratorios negativos han sido compensados por los saldos positivos de crecimiento vegetativo que presentan los municipios gaditanos en el periodo analizado (que ascienden a 48.401 personas). En este sentido, es necesario destacar el fuerte crecimiento vegetativo experimentado en los municipios de Jerez de la Frontera (8.196 personas), El Puerto de Santa María (4.711), San Fernando (4.579), Chiclana de la Frontera (4.402), Algeciras (3.746), Sanlúcar de Barrameda (3.651), Rota (2.925) y Puerto Real (2.055), aunque prácticamente todos los municipios han experimentado crecimientos positivos (salvo Cádiz, con un saldo negativo de 180 personas y El Gastor con un saldo de 26 personas), haciendo que el crecimiento demográfico neto sea de 33.748 personas.

A pesar de la simplicidad que pueda presentar el análisis de tasas e índices que se viene llevando a cabo en esta parte del trabajo, lo que sí es cierto es que ha permitido establecer una primera aproximación a algunos cambios y propensiones de cierto calado en el comportamiento de los distintos municipios dentro del conjunto provincial. Nuestra intención no ha sido otra que la de poner de relieve una serie de tendencias que no pueden ni deben quedar en la sombra cuando se aborda un análisis sobre la convergencia/ divergencia intermunicipal como el que pretendemos llevar a cabo.

\section{El proceso de convergencia en el periodo 1991-2000}

Las investigaciones sobre disparidades económicas territoriales fueron impulsadas por el desarrollo de los modelos neoclásicos de crecimiento económico (Borts y Stein, 1964), a los que siguieron los modelos de causación circular acumulativa (Kaldor, 1970). En la actualidad existen dos corrientes sobre crecimiento económico abiertas: por un lado, los análisis basados en el modelo de crecimiento de Robert Solow ${ }^{10}$ (Barro y Sala-i-Martín, 1992); y por otro lado, los modelos de crecimiento endógeno (Romer, 1986; Lucas,

\footnotetext{
${ }^{10}$ Premio nobel en 1987 precisamente por sus contribuciones al crecimiento económico.
} 
1988). Las diferencias entre estas dos líneas de trabajo es que predicen tanto la convergencia como la divergencia en función de las hipótesis de comportamiento de las que parten.

La existencia de diferencias de renta o VAB entre territorios y su posible tendencia histórica a incrementarse o a disminuir ha sido una cuestión en la que se han centrado muchas teorías sobre las relaciones interterritoriales. Recientemente, la evolución de las disparidades territoriales se ha planteado en términos de convergencia económica. Esta preocupación por la evolución de las disparidades económicas ha experimentado un resurgimiento de la mano de los nuevos teóricos del crecimiento que han acuñado dos conceptos específicos de convergencia muy extendidos en la literatura (Sala-i-Martín, 1990, 1994): la convergencia sigma, que viene a darse cuando la dispersión de la renta per cápita de un grupo de territorios tiende a disminuir a lo largo del tiempo, midiéndose normalmente mediante la desviación típica muestral; y la convergencia beta, que intenta constatar, para un conjunto de territorios, si existe una covariación negativa entre la tasa de crecimiento de la renta real per cápita y el nivel inicial de ésta, o lo que es lo mismo, si los territorios más pobres tienden a crecer más rápidamente que los territorios ricos, de forma que todos ellos tiendan a un mismo nivel, produciéndose un efecto de caza o catching-up (Sala-i-Martín, 1996, 1999; Cuadrado, Mancha y Garrido, 1998; Cuadrado, Garrido y Mancha, 1999).

Figura núm. 8

Convergencia sigma en VABpc

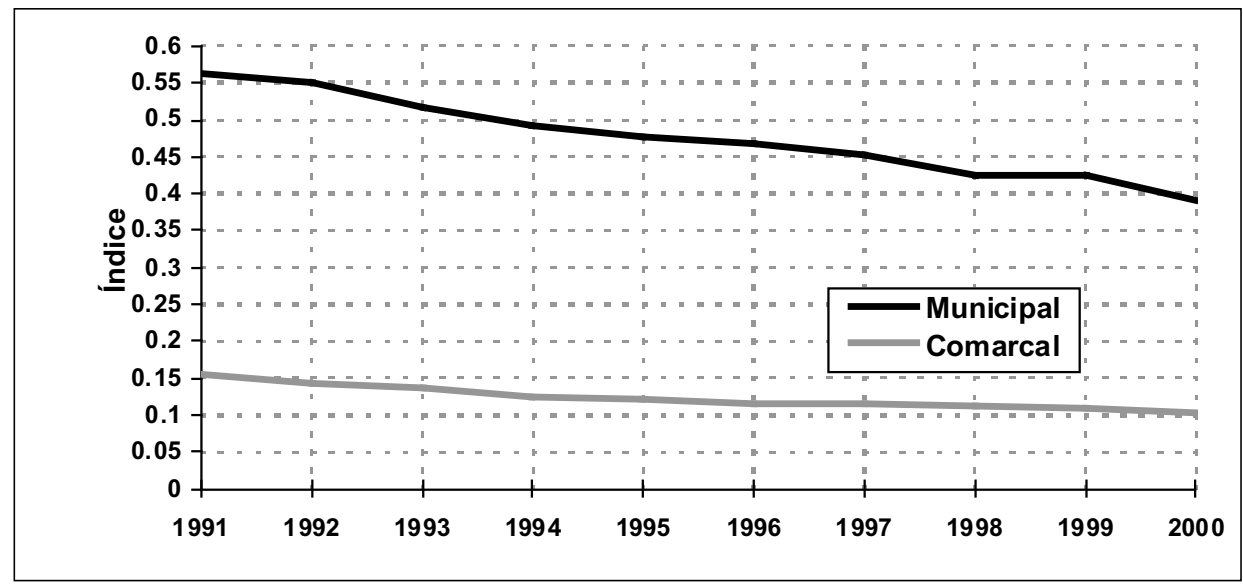

FUENTE: Elaboración propia. 
El resultado más significativo de nuestro análisis señala que entre los municipios y comarcas de Cádiz se ha producido, en el periodo analizado (1991-2000), un proceso tendencialmente convergente, es decir, se ha producido un continuo proceso de acercamiento en VABpc o de reducción de las desigualdades intermunicipales en VABpc (figura núm. 8), lo que puede ser debido, bien a que las pautas de crecimiento económico territorial se han ajustado a las predicciones de los modelos neoclásicos, bien a que las políticas económicas orientadas a una mayor equidad personal en la distribución del VAB están teniendo éxito, bien a una cierta combinación de ambas causas.

A continuación se ha elaborado, tomando como indicador básico la variación experimentada en el VABpc relativo de cada municipio, expresada en puntos porcentuales (véase cuadro núm. 3), una sencilla tipología que permita distinguir entre municipios que han contribuido a la convergencia, municipios que han contribuido a la divergencia y municipios que han tenido, en este terreno, un comportamiento neutral. ${ }^{11}$ En concreto, y prestando atención a la totalidad del periodo objeto de consideración, se pueden diferenciar los siguientes grupos de municipios:

a) La gran mayoría de municipios ( 31 de los 42 considerados en el estudio $^{12}$ ) tuvieron un comportamiento convergente positivo, mientras que por el lado negativo se encuentran Algeciras, Cádiz, El Puerto de Santa María, Rota y Sanlúcar de Barrameda.

b) Los municipios divergentes fueron, por el lado positivo, Los Barrios y San Roque, y por el lado negativo, La Línea de la Concepción y San Fernando.

c) Los únicos municipios que tuvieron un comportamiento neutro en el periodo analizado fueron Jerez de la Frontera y Puerto Real.

\footnotetext{
${ }^{11}$ Entendemos que el proceso de convergencia es positivo cuando una provincia con un VABpc inferior a la media regional mejora su posición con el tiempo, mientras que el proceso tiene un sesgo negativo cuando una provincia con VABpc superior a la media regional empeora su posición relativa. Por otro lado, entendemos que el proceso de divergencia es positivo cuando una región con $\mathrm{VABpc}$ superior a la media regional mejora su posición con el tiempo, mientras que el proceso tiene un sesgo negativo cuando una región con VABpc inferior a la media regional empeora su posición relativa.

${ }^{12}$ Ya que de los municipios de Benalup-Casas Viejas y San José del Valle no contamos con datos para periodos anteriores a 1992 y 1995, respectivamente, ya que aún no eran considerados como tal.
} 
Una vez analizada la convergencia sigma, sería factible ensayar una sencilla ecuación de regresión que permita contrastar si una situación de retraso relativo en un momento dado tiende a reducirse con el paso del tiempo (Martín Rodríguez, 1998). En definitiva, se trata de comprobar si los municipios más pobres crecen a una tasa mayor que los más ricos, de forma que todas las economías tiendan al mismo nivel que podríamos denominar como estado estacionario (Solow, 1956).

Figura núm. 9

Convergencia beta de los municipios gaditanos en VABpc (1991-2000)

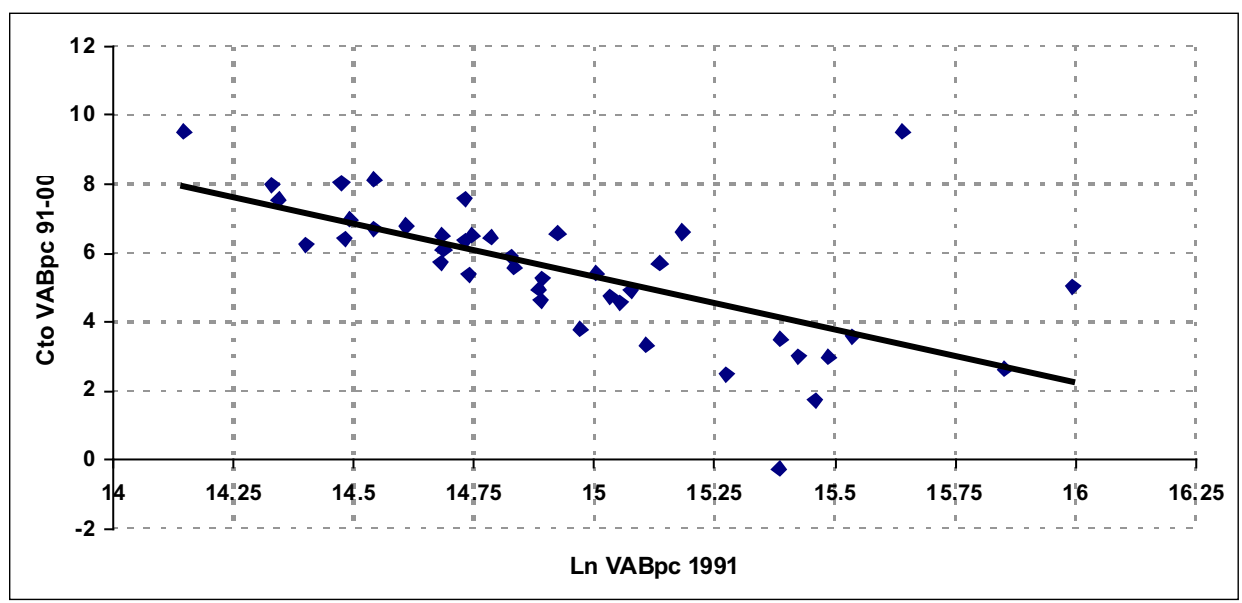

FUENTE: Elaboración propia.

En la figura núm. 9 presentamos la comparación entre la posición que tenían cada municipio referido al VABpc en el año 1991 y el crecimiento anual acumulado del mismo en el periodo 1991-2000. Se observa que entre los municipios gaditanos se ha producido un proceso de convergencia beta en el periodo 1991-2000 que responde al siguiente modelo de regresión mínimo cuadrado ordinario: 
Cuadro núm. 6

Convergencia beta de los municipios gaditanos (1991-2000)

\begin{tabular}{|c|c|}
\hline \multicolumn{2}{|c|}{$\begin{array}{l}\text { Variable dependiente: Cto. VABpc 91-00 } \\
\text { MCO }\end{array}$} \\
\hline Estimaciones & Coeficientes \\
\hline Constante & $51,499790 \quad(* * *)$ \\
\hline $\mathrm{Ln}(\mathrm{VABpc} 91)$ & $-3,079243(* * *)$ \\
\hline $\mathrm{R}^{2}$ & 0,413175 \\
\hline $\mathrm{R}^{2}$ ajustado & 0,398505 \\
\hline Test de White (n R²) & 7,744946 \\
\hline $\mathrm{F}$ & 28,163450 \\
\hline $\mathrm{n}$ & 42 \\
\hline \multicolumn{2}{|c|}{$\begin{array}{l}\text { NOTA: (*) Significativo a un nivel de confianza de } 90 \% \text {. } \\
(* *) \text { Significativo a un nivel de confianza de } 95 \% \text {. } \\
(* * *) \text { Significativo a un nivel de confianza de } 99 \% \text {. }\end{array}$} \\
\hline
\end{tabular}

FUENTE: Elaboración propia.

Por tanto, la velocidad de convergencia beta estimada en el periodo analizado ha sido de 3,08\% de reducción media anual de las disparidades, muy superior a la experimentada por las comarcas andaluzas en prácticamente el mismo periodo (1991-1999), que fue de $0,73 \%{ }^{13}$

$\mathrm{El}$ análisis de la convergencia sigma y beta ha puesto de manifiesto el proceso de acercamiento que ha tenido lugar entre los niveles de desarrollo de los distintos municipios gaditanos, pero no deja de ser cierto que no ofrece información alguna acerca de la posición relativa de cada una de ellos, y de cuál ha sido su evolución a lo largo del tiempo. Éste es, sin embargo, un aspecto muy importante desde el punto de vista económico y social, ya que el fenómeno de la mayor o menor movilidad en la posición relativa de cada municipio en el contexto provincial constituye indudablemente un elemento inicial para evaluar, éticamente, si el grado de desigualdad existente entre los municipios gaditanos es preocupante o

${ }^{13}$ Dato extraído de Peña Sánchez (2006). 
no (García Greciano et al., 1995; Ezcurra et al., 2003). Si comparamos dos distribuciones con la misma desigualdad, diremos que es mejor aquella que ofrezca una mayor movilidad, es decir, la que produzca un mayor intercambio de posiciones sobre una situación de referencia. En cualquier ámbito territorial esto es así, pues una mayor movilidad indicaría una menor consolidación de las posiciones de partida o, si se quiere, una menor necesidad de políticas territoriales compensatorias (Salas, 1999), disminuyendo en gran medida la valoración negativa que merecen las desigualdades interterritorales, ya que la esperanza de salir de una situación desfavorable sería más alta. ${ }^{14}$ Por el contrario, si la movilidad fuese pequeña, esto añadiría un factor adicional de preocupación. ${ }^{15}$

Una cuestión a tener en cuenta es que el horizonte temporal considerado es de tan sólo 10 años, lo que en principio se podría considerar como un periodo no muy amplio para establecer el grado de movilidad de los cambios de posición en el ranking municipal de la provincia de Cádiz. A pesar de lo anterior, se advierte que los municipios gaditanos han mostrado una escasa movilidad en el periodo analizado 1991-2000. De los 10 municipios que ocupaban las primeras posiciones en 1991 permanecen 8 en el año 2000, y de los 10 municipios que ocupaban las últimas posiciones en 1991 permanecen 9 en el año 2000 (véase cuadro Núm. 3). Por consiguiente, ha existido una fuerte cristalización de las posiciones que ocupan los municipios en el ranking municipal según su VABpc, lo que en cierta manera puede generar una comprensible preocupación en determinados ámbitos políticos y sociales por el enquistamiento de las desigualdades económicas intermunicipales.

Teniendo en cuenta lo anterior, sí se observan fuertes cambios de posición en algunos municipios como, por un lado, en sentido positivo, Benaocaz, Conil de la Frontera y Castellar de la Frontera, que ganan 9, 7 y 6 puestos, respectivamente; por otro lado, en sentido negativo, Sanlúcar de Barrameda, Ubrique, Prado del Rey y Barbate, que pierden 11, 9 y 7 puestos (las dos últimas), respectivamente.

\footnotetext{
${ }^{14}$ En este contexto, la política territorial debería centrarse básicamente en la necesidad de paliar los efectos adversos de los ciclos económicos, dejando en un segundo plano las políticas tradicionales de convergencia.

${ }^{15}$ En este caso, la necesidad de una política activa de reducción de las disparidades municipales quedaría reforzada.
} 
Por tanto, la idea que subyace a todo el razonamiento expuesto no es que se esté produciendo una equiparación en la distribución de la producción generada entre los ciudadanos de la provincia de Cádiz, sino que se está igualando el VABpc medio de los municipios gaditanos. Lógicamente con ello no podemos afirmar que los ciudadanos de esta provincia estén consiguiendo el mismo nivel de desarrollo y bienestar económico. Pero lo que sí es cierto es que la convergencia municipal en VABpc podría suponer un avance importante en la reducción de la desigualdad económica de la población, pues suponemos que podría ser más viable reducir disparidades económicas entre la población de una provincia cuando partimos de una situación de reparto equilibrado del VABpc entre los municipios. ${ }^{16}$

\section{Algunos factores explicativos de las disparidades económicas municipales en la provincia de Cádiz}

Esta sección tratará de poner de manifiesto el comportamiento que han tenido algunos factores explicativos de las disparidades económicas territoriales en la provincia de Cádiz como son la distribución y concentración de la población, la productividad aparente del trabajo y la estructura productiva de cada uno de los municipios gaditanos. $Y$ dichos factores se analizarán desde un doble enfoque. Por un lado, se examinará la influencia de dichos factores en el nivel de desarrollo económico de los municipios gaditanos, de forma estática a partir de un análisis transversal y, por otro lado, se estudiará la relación de los cambios experimentados en dichos factores explicativos en el ritmo de crecimiento económico territorial en el periodo analizado, de una forma dinámica.

Pero antes de todo ello, creemos necesario establecer el grado de influencia de las disparidades en población en las desigualdades económicas de los municipios de la provincia de Cádiz. Así, a partir de la siguiente relación:

\footnotetext{
${ }^{16}$ Aunque sólo sea como información adicional, en un trabajo de Goerlich y Mas (1999) se pone de manifiesto, tras la aplicación de varios índices (Gini, Theil y Atkinson), a la distribución por deciles de población de los ingresos de la provincia de Cádiz, utilizando la base de datos ofrecida por la Encuesta de Presupuestos Familiares para los años 73/74, 80/81 y 91/91, que no parece que haya habido un avance sustancial en la reducción de las desigualdades, ya que, según los valores que arrojan los índices utilizados, las diferencias existentes en los años 90/91 se han mantenido al mismo nivel que las que presentaban en el año 73/74.
} 
$V A B p c=\frac{V A B}{\text { Población }} \quad$ y tomando logaritmos $\ln (V A B)=\ln ($ Población $)+$

In (VABpc) se consigue descomponer la varianza del logaritmo del VAB global en la varianza del logaritmo de la población, la varianza del logaritmo del VABpc y la covarianza de las dos variables anteriores. ${ }^{17}$

Cuadro núm. 7

Descomposición de factores explicativos de la convergencia de los municipios de Cádiz en VABpc

\begin{tabular}{|c|c|c|c|c|c|c|c|}
\hline & & & & & \multicolumn{3}{|c|}{ PORCENTAJES } \\
\hline & VAR(Ln(VAB) & VAR(LnPob) & VAR(LnVABpc) & $2 * \operatorname{Cov}$ & VAR(LnPob) & VAR(LnVABpc) & $2 * \operatorname{Cov}$ \\
\hline 1991 & 3,00425958 & 2,05170455 & 0,17600089 & 0,77655414 & 68,29 & 5,86 & 25,85 \\
\hline 1992 & 2,94289308 & 2,00926928 & 0,18110120 & 0,69932307 & 68,28 & 6,15 & 23,76 \\
\hline 1993 & 2,88911502 & 2,02733887 & 0,16159656 & 0,64827722 & 70,17 & 5,59 & 22,44 \\
\hline 1994 & 2,84889292 & 2,03328468 & 0,15285928 & 0,61222204 & 71,37 & 5,37 & 21,49 \\
\hline 1995 & 2,81143665 & 2,03687403 & 0,15055202 & 0,57412413 & 72,45 & 5,35 & 20,42 \\
\hline 1996 & 2,75733854 & 2,03672952 & 0,14167637 & 0,57033478 & 73,87 & 5,14 & 20,68 \\
\hline 1997 & 2,73612476 & 2,04262655 & 0,13347497 & 0,55159507 & 74,65 & 4,88 & 20,16 \\
\hline 1998 & 2,68865905 & 2,06294312 & 0,11884130 & 0,49952713 & 76,73 & 4,42 & 18,58 \\
\hline 1999 & 2,70240674 & 2,07471795 & 0,12024622 & 0,49954298 & 76,77 & 4,45 & 18,49 \\
\hline 2000 & 2,60118716 & 2,04488593 & 0,10848218 & 0,44781906 & 78,61 & 4,17 & 17,22 \\
\hline \multicolumn{8}{|l|}{ Notas: } \\
\hline & \multicolumn{3}{|c|}{ LnVAB: Logaritmo neperiano del VAB. } & & & & \\
\hline & \multicolumn{3}{|c|}{ LnPob: Logaritmo neperiano de la Población. } & & & & \\
\hline & \multicolumn{4}{|c|}{ LnVABpc: Logaritmo neperiano del VAB per cápita. } & & & \\
\hline
\end{tabular}

FUENTE: Elaboración propia.

Los resultados obtenidos (cuadro núm. 7) indican claramente cómo el proceso de convergencia en VABpc se ha producido fundamentalmente por la disminución de la desigualdad en VAB, ya que, como podemos observar, la desigualdad en población (medido a partir de la varianza del logaritmo de la población) apenas ha variado en el periodo analizado. En la explicación del proceso de convergencia registrado por el VAB global de los municipios gaditanos, la participación de las diferencias demográficas va siendo cada vez mayor, pasando de 68,29\% en 1991 a 78,61\% en 2000 , debido a la práctica paralización de las desigualdades en población y a la disminución de las disparidades en VABpc. Por tanto, la reducción de disparidades en VABpc ha venido acompañado por el proceso de convergencia en $\mathrm{VAB}$ y al mantenimiento de la dispersión en población, lo que

${ }^{17}$ Del mismo modo, esta técnica es utilizada para el caso de las regiones españolas por García-Greciano y Raymond Bara (1999). 
origina que este último aspecto participe en una mayor proporción en las diferencias económicas de los municipios de la provincia de Cádiz.

Del mismo modo, se pretende considerar como factores explicativos del heterogéneo comportamiento del VABpc de cada uno de los municipios gaditanos la desigual distribución de la productividad aparente del empleo $(\theta)$ y de los empleos per cápita $(N p c)$ :

$V A B p c=\theta * N p c$, si se toman logaritmos, $\ln (V A B p c)=\ln (\theta)+$ $\ln (\mathrm{Npc})$ lo que permite examinar la evolución de la convergencia seguida por estas dos variables.

Cuadro núm. 8

Descomposición de la varianza en la evolución del logaritmo del VABpc

\begin{tabular}{|c|c|c|c|c|c|c|c|}
\hline & & & & & \multicolumn{3}{|c|}{ PORCENTAJES } \\
\hline & VAR(LnVABpc) & VAR(LnNpc) & VAR(Ln $\theta)$ & $2 * \operatorname{Cov}$ & VAR(LnNpc) & VAR(Lnt) & $2 * \operatorname{Cov}$ \\
\hline 1991 & 0,17600089 & 0,02177232 & 0,16646959 & $-0,01224102$ & 12,37 & 94,58 & $-6,95$ \\
\hline 2000 & 0,10488218 & 0,02760123 & 0,06880127 & 0,01207967 & 25,44 & 63,42 & 11,14 \\
\hline \multirow{2}{*}{\multicolumn{8}{|c|}{ LnVABpc: Logaritmo neperiano del VAB per cápita. }} \\
\hline & \multicolumn{7}{|c|}{ LnVABpc: Logaritmo neperiano del VAB per cápita. } \\
\hline & \multirow{2}{*}{\multicolumn{7}{|c|}{ LnNpc: Logaritmo neperiano del Empleo per cápita. }} \\
\hline & & & & & & & \\
\hline
\end{tabular}

FUENTE: Elaboración propia.

La descomposición anterior muestra, en primer lugar, cómo la disminución de las desigualdades en VABpc ha venido acompañada, en el periodo analizado, por una disminución de las disparidades en productividad aparente del empleo, mientras que los empleos per cápita han sufrido un ligero aumento en el grado de dispersión; en segundo lugar, se advierte que la varianza del logaritmo del VABpc, al principio del periodo analizado (1991), venía explicada en un $94,58 \%$ por las diferencias en productividad, mientras que $12,37 \%$ se debía a las diferencias en los empleos per cápita, y -6,95\% restante a la interacción de ambos efectos, mientras que, en el periodo final (2000), venía explicada en tan sólo 63,42\% por las diferencias en productividad, 25,44\% por las diferencias en empleos per cápita y $11,14 \%$ restante por la relación de los dos anteriores. ${ }^{18}$ Por tanto,

\footnotetext{
${ }^{18}$ Para contrastar los resultados obtenidos anteriormente, se ha realizado una prueba paralela consistente en analizar la contribución de la variabillidad de la productividad y los empleos per cápita en las desigualdades en VABpc a partir de la descomposición del índice de Theil. Se constata que en 1991 80,84\% de la dispersión municipal en VABpc era debido
} 
la dinámica convergente del VABpc de los municipios gaditanos ha venido explicado fundamentalmente por el acercamiento entre éstos en productividad aparente del empleo, aunque es cierto que éste ha ido reduciendo su dimensión, aumentando el grado de explicación dado por el proceso seguido por los empleos per cápita.

Del análisis realizado anteriormente se desprenden dos ideas de enorme interés. La primera es que las diferencias en productividad están perdiendo peso progresivamente en la explicación de las disparidades en los niveles de desarrollo económico de los municipios gaditanos. Dado que la divergencia de los empleos per cápita están ganando peso al explicar la evolución de las disparidades en VABpc, éste ha impedido que los avances de convergencia en productividad se hayan traducido definitivamente en convergencia del nivel de desarrollo gaditano. Por consiguiente, en tanto las disparidades en empleos per cápita siga la misma tendencia en el futuro y explique cada vez en mayor medida el proceso convergente/divergente seguido por el nivel de desarrollo económico entre los municipios gaditanos, se producirá un proceso de interrupción de la convergencia en VABpc entre los municipios gaditanos. Este razonamiento tiene una gran relevancia desde el punto de vista de la política económica ya que una reducción en las disparidades existentes en el mercado de trabajo sería una condición necesaria para seguir avanzando en la reducción de las disparidades municipales en la provincia de Cádiz. ${ }^{19}$ La segunda, y partiendo del último dato que presenta la varianza del logaritmo de la productividad aparente del trabajo en el año 2000 (o,06880127), en la medida en que la convergencia en productividad muestre síntomas de agotamiento, desaparecerá una fuente de convergencia en VABpc. Por tanto, cabe cuestionarse si la convergencia en productividad aparente del trabajo está muy agotada o si, por el contrario, cabe esperar que avance en el futuro.

a las disparidades en productividad y $19,16 \%$ a la de los efectos laborales, mientras que en el año 2000 dichas proporciones eran de $64,74 \%$ y 35,26\%, respectivamente. Por tanto, la productividad aparente del empleo es un factor cuya dispersión está perdiendo impulso en las disparidades en VABpc en la provincia de Cádiz, siendo la variabilidad de los efectos laborales los que están adquiriendo cada vez más importancia.

${ }^{19}$ A idéntica conclusión llegan, para el caso español, Villaverde Castro (1999), y para el caso andaluz, Peña Sánchez (2006). 
A continuación se complementa el estudio de los factores explicativos de las diferencias existentes en el nivel de desarrollo económico de los municipios de la provincia de Cádiz a partir de modelos lineales de regresión por mínimos cuadrados ordinarios (MCO), intentando establecer los parámetros y coeficientes que permita medir la influencia de cada factor explicativo en el nivel de renta per cápita y del crecimiento de ésta en los municipios gaditanos.

La estrategia seguida para dicho análisis ha sido la siguiente: En primer lugar, para establecer las relaciones existentes entre las variables analizadas, se plantea la matriz de correlaciones entre todos los factores explicativos que pretendemos analizar. En segundo lugar, se estima el modelo lineal por MCO con los factores explicativos de forma conjunta, presentando algunas ecuaciones que permitan establecer la influencia de dichos factores explicativos sobre la variable explicada. En tercer lugar, como se ha evidenciado un claro problema de multicolinealidad, se decide plantear regresiones parciales, con el fin de determinar el grado de influencia individual de cada factor explicativo. Y por último, en los casos en los que se ha precisado (por la presencia de heterocedasticidad) se aplica la corrección de White.

Cuadro núm. 9

Matriz de correlaciones (nivel de desarrollo: VABpc)

\begin{tabular}{|l|c|c|c|c|c|c|c|}
\hline & VABpc & DP & Productiv & EPagri & EPindust & EPconstr & EPserv \\
\hline VABpc & 1,000000 & 0,135562 & 0,963335 & $-0,620305$ & 0,242079 & $-0,180546$ & 0,538428 \\
\hline DP & 0,135562 & 1,000000 & 0,143709 & $-0,335968$ & 0,060719 & $-0,403735$ & 0,476910 \\
\hline Productiv & 0,963335 & 0,143709 & 1,000000 & $-0,611678$ & 0,184333 & $-0,193930$ & 0,576684 \\
\hline EPagri & $-0,620305$ & $-0,335968$ & $-0,611678$ & 1,000000 & $-0,580010$ & 0,413576 & $-0,772403$ \\
\hline EPindust & 0,242079 & 0,060719 & 0,184333 & $-0,580010$ & 1,000000 & $-0,468507$ & 0,056762 \\
\hline EPconstr & $-0,180546$ & $-0,403735$ & $-0,193930$ & 0,413576 & $-0,468507$ & 1,000000 & $-0,534879$ \\
\hline EPserv & 0,538428 & 0,476910 & 0,576684 & $-0,772403$ & 0,056762 & $-0,534879$ & 1,000000 \\
\hline
\end{tabular}

NOTAS: VABpc: Valor añadido bruto por habitante. DP: Densidad de Población. Productiv: Productividad aparente del empleo.

FUENTE: Elaboración propia.
EPagri: Especialización productiva agrícola. EPindust: Especialización productiva industrial. EPconstr: Especialización productiva construcción. EPserv: Especialización productiva servicios. 
Cuadro núm. 10

Matriz de correlaciones (crecimiento del nivel de desarrollo: CtoVABpc)

\begin{tabular}{|c|r|r|r|r|r|r|r|}
\hline & \multicolumn{1}{|c|}{ CtoVABpc } & \multicolumn{1}{c|}{ CtoDP } & \multicolumn{1}{c|}{ CtoProd } & \multicolumn{1}{c|}{ Ctoagri } & \multicolumn{1}{c|}{ Ctoindust } & \multicolumn{1}{l|}{ Ctoconstr } & \multicolumn{1}{c|}{ Ctoserv } \\
\hline CtoVABpc & 1,000000 & $-0,192703$ & 0,759865 & $-0,264170$ & 0,363818 & 0,167194 & 0,033342 \\
\hline CtoDP & $-0,192703$ & 1,000000 & $-0,206674$ & 0,372549 & 0,099123 & 0,245131 & 0,767278 \\
\hline CtoProd & 0,759865 & $-0,206674$ & 1,000000 & $-0,650460$ & 0,108409 & 0,281480 & $-0,210837$ \\
\hline Ctoagri & $-0,264170$ & 0,372549 & $-0,650460$ & 1,000000 & $-0,018846$ & $-0,394005$ & 0,301866 \\
\hline Ctoindust & 0,363818 & 0,099123 & 0,108409 & $-0,018846$ & 1,000000 & 0,379075 & 0,263609 \\
\hline Ctoconstr & 0,167194 & 0,245131 & 0,281480 & $-0,394005$ & 0,379075 & 1,000000 & 0,231901 \\
\hline Ctoserv & 0,033342 & 0,767278 & $-0,210837$ & 0,301866 & 0,263609 & 0,231901 & 1,000000 \\
\hline
\end{tabular}

NOTAS: CtoVABpc: Crecimiento del Valor añadido bruto por habitante. CtoDP: Crecimiento de la Densidad de Población.

Ctoagri: Crecimiento del sector agrario. CtoProd: Crecimiento de la Productividad aparente del empleo.

FUENTE: Elaboración propia.

En las matrices de correlaciones presentadas en los cuadros núm. 9 y 10 se observa como el problema de multicolinealidad es evidente por la fuerte correlación que presentan algunos de los factores que se han considerado como explicativos tanto del nivel de desarrollo económico como del crecimiento del mismo en los municipios de la provincia de Cádiz. Lo anterior hace tomar los resultados de las estimaciones con la cautela necesaria, ya que es imposible suponer en estos casos la hipótesis ceteris paribus, es decir, establecer lo que cambiaría la variable dependiente ante un cambio en una variable independiente suponiendo que el resto de las variables permanecen constantes, al existir altas correlaciones en las mismas.

Cuadro Núm. 11

\begin{tabular}{|c|c|c|c|c|c|c|c|}
\hline \multicolumn{8}{|c|}{ Variable dependiente: VAB per cápita } \\
\hline \multicolumn{8}{|c|}{\begin{tabular}{|l|l|l|} 
MCO & \\
\end{tabular}} \\
\hline Estimaciones & 1 & 2 & 3 & 4 & 5 & 6 & 7 \\
\hline Constante & $-127,9579$ & 80,7969 (***) & $-25,5262(* * *)$ & $120,2333(* * *)$ & $69,8908(* * *)$ & $102,5674(* * *)$ & 3,4311 \\
\hline DP & 0,0005 & $0,0040(* * *)$ & & & & & \\
\hline Productiv & $1,2730(* * *)$ & & $1,2885(* * *)$ & & & & \\
\hline EPagri & 0,0879 & & & $-0,1745(* * *)$ & & & \\
\hline EPindust & 0,1880 & & & & 0,1412 & & \\
\hline EPconstr & 0,1699 & & & & & $-0,1543(*)$ & \\
\hline EPserv & 0,5810 & & & & & & $1,0048(* * *)$ \\
\hline $\mathrm{R}^{2}$ & 0,9350 & 0,0184 & 0,9280 & 0,3848 & 0,0586 & 0,0326 & 0,2899 \\
\hline $\mathrm{R}^{2}$ ajustado & 0,9238 & $-0,0062$ & 0,9262 & 0,3694 & 0,0351 & 0,0084 & 0,2722 \\
\hline Test de White & 32,3740 & 0,3998 & 1,4459 & 5,5369 & 2,7886 & 1,3879 & 2,0739 \\
\hline F & 83,8813 & 0,7488 & 515,6631 & 25,0173 & 2,4900 & 1,3478 & 16,3305 \\
\hline \multicolumn{8}{|c|}{ NOTA: $(*)$ Significativo a un nivel de confianza de $90 \%$. } \\
\hline \multicolumn{8}{|c|}{$(* *)$ Significativo a un nivel de confianza de $95 \%$. } \\
\hline \multicolumn{4}{|c|}{$(* * *)$ Significativo a un nivel de confianza de $99 \%$. } & & & & \\
\hline
\end{tabular}

FUENTE: Elaboración propia. 


\section{Cuadro núm. 12}

Relación crecimiento del VABpc y crecimiento de factores explicativos

\begin{tabular}{|c|c|c|c|c|c|c|c|}
\hline \multicolumn{8}{|c|}{ Variable dependiente: VAB per cápita } \\
\hline \multicolumn{8}{|l|}{ MCO } \\
\hline Estimaciones & 1 & 2 & 3 & 4 & 5 & 6 & 7 \\
\hline Constante & $-127,9579$ & 80,7969 (***) $^{*}$ & $-25,5262(* * *)$ & 120,2333 (***) & $69,8908(* * *)$ & $102,5674(* * *)$ & 3,4311 \\
\hline $\mathrm{DP}$ & 0,0005 & $0,0040(* * *)$ & & & & & \\
\hline Productiv & $1,2730(* * *)$ & & $1,2885(* * *)$ & & & & \\
\hline EPagri & 0,0879 & & & $-0,1745(* * *)$ & & & \\
\hline EPindust & 0,1880 & & & & 0,1412 & & \\
\hline EPconstr & 0,1699 & & & & & $-0,1543(*)$ & \\
\hline EPserv & 0,5810 & & & & & & $1,0048(* * *)$ \\
\hline $\mathrm{R}^{2}$ & 0,9350 & 0,0184 & 0,9280 & 0,3848 & 0,0586 & 0,0326 & 0,2899 \\
\hline $\mathrm{R}^{2}$ ajustado & 0,9238 & $-0,0062$ & 0,9262 & 0,3694 & 0,0351 & 0,0084 & 0,2722 \\
\hline Test de White & 32,3740 & 0,3998 & 1,4459 & 5,5369 & 2,7886 & 1,3879 & 2,0739 \\
\hline F & 83,8813 & 0,7488 & 515,6631 & 25,0173 & 2,4900 & 1,3478 & 16,3305 \\
\hline \multicolumn{8}{|c|}{ NOTA: $(*)$ Significativo a un nivel de confianza de $90 \%$. } \\
\hline \multicolumn{8}{|c|}{$(* *)$ Significativo a un nivel de confianza de $95 \%$. } \\
\hline$(* * *)$ Sign & ativo a un nivel d & confianza de & & & & & \\
\hline
\end{tabular}

FUENTE: Elaboración propia.

En las tablas anteriores se ha presentado una relación conjunta de los factores explicativos en los dos casos que estamos analizando, así como las relaciones parciales, para evitar el problema de multicolinealidad anteriormente señalado. Los resultados obtenidos son muy reveladores a la hora de explicar por qué unos municipios en Cádiz, en el periodo analizado, cuentan con un nivel de desarrollo económico mayor y por qué unos municipios crecen más que otros: a) por lo general, los municipios más desarrollados económicamente son los que cuentan con una mayor densidad de población (0,004), una mayor productividad $(1,2885)$ y una mayor especialización en el sector servicios (1,0048); sin embargo, la especialización agraria ha afectado de forma negativa en el nivel de desarrollo económico como así muestra el parámetro obtenido en la cuarta estimación presentada en la tabla 11 (-0,1745); en todos los casos, el nivel de significación de los parámetros estimados es superior a 99\%; b) el crecimiento en el nivel de desarrollo económico de los municipios gaditanos ha venido condicionado por el crecimiento de la productividad (0,4628, con un nivel de significación de 99\%) y por el crecimiento del sector industrial (0,2205, con un nivel de significación de 95\%), este último probablemente debido a la mayor productividad de este sector con respecto al resto de los sectores productivos.

Por consiguiente, se observa cómo la productividad aparente del empleo así como la estructura sectorial están jugando un papel fundamental tanto en el nivel de desarrollo económico como en su crecimiento en el conjunto de los municipios de Cádiz. 


\section{Conclusiones}

Las conclusiones que se desprenden del trabajo llevado a cabo sobre las disparidades económicas en el interior de la provincia de Cádiz en el periodo 1991-2000 son las siguientes:

a) La convergencia real en VAB per cápita de la provincia de Cádiz respecto a su entorno regional y nacional ha mostrado en el periodo 19551998 una tendencia claramente descendente según los datos utilizados de la Fundación BBVA. No obstante, en los últimos años 1998-2002, utilizando los datos de la Contabilidad Regional del Instituto Nacional de Estadística, se detecta un leve proceso convergente. El proceso divergente del primer periodo (1955-1998) fue debido fundamentalmente al menor crecimiento anual acumulativo del VAB unido a un crecimiento más intenso de la población. Sin embargo, en el último periodo analizado (1998-2002) el mayor crecimiento del VAB y el menor crecimiento de la población han originado un proceso convergente en el nivel de desarrollo económico.

b) La aportación del sector servicios en la estructura sectorial de la provincia de Cádiz es superior a 60\%, hecho similar al del conjunto regional y nacional debido al proceso de terciarización que se viene dando en el conjunto del territorio español. También destaca el sector agrario e industrial en su tejido productivo, por la mayor productividad aparente en el empleo que presenta con respecto a Andalucía y a España.

c) Las fuertes disparidades económicas entre los municipios gaditanos en VAB per cápita son evidentes. De hecho, los municipios de la zona costera presentan mayor grado de prosperidad económica frente a los municipios de la Sierra, más deprimidos económicamente. No obstante, dichas diferencias económicas se han ido reduciendo en el periodo analizado 1991-2000 como así demuestra el análisis de la convergencia sigma y beta de los municipios gaditanos, produciéndose un proceso de convergencia en VAB per cápita con una velocidad de 3,08\%, muy superior a la experimentada por las comarcas andaluzas de 0,73\% en el periodo 1991-1999. Además, es necesario tener en cuenta que el grado de movilidad de los municipios gaditanos ha sido muy escaso, aspecto que sin duda puede perjudicar en cierta manera futuros procesos de convergencia.

d) Por lo general, el crecimiento de la población ha sido mayor en los municipios que partían con un mayor nivel de desarrollo económico en el 
año 1991, por lo que deducimos que la concentración de la población ha aumentado en aquellos municipios más desarrollados económicamente y que, por tanto, contaban con mayores oportunidades en el mercado laboral. En este sentido, la mayor parte de los municipios han experimentado saldos migratorios negativos, posiblemente debido al menor nivel de desarrollo económico que presentaba la provincia de Cádiz respecto a otros territorios andaluces y españoles, con mayor capacidad de absorción de mano de obra. No obstante, dichos saldos migratorios negativos han sido compensados por los saldos positivos de crecimiento vegetativo, lo que finalmente ha originado un crecimiento neto positivo de la población.

e) La reducción de las disparidades económicas de los municipios gaditanos ha venido explicado fundamentalmente por la reducción de las disparidades en productividad aparente del empleo, aunque la explicación del proceso de convergencia en esta última ha sido cada vez menor, aumentando el grado de influencia de las disparidades en el mercado de trabajo, por lo que dicho aspecto sería necesario tenerlo en cuenta a la hora de diseñar políticas tendentes a reducir los desequilibrios económicos territoriales en la provincia de Cádiz.

f) La aglomeración de población, la productividad aparente del empleo y la estructura sectorial han sido factores que han influido en el nivel de desarrollo económico de los municipios gaditanos. Por un lado, en general, los municipios más prósperos son los que han contado con una mayor densidad de población, una mayor productividad aparente del empleo y una mayor especialización en el sector terciario; en cambio, la especialización agraria ha influido de forma negativa en el nivel de prosperidad. Por otro lado, el crecimiento en el nivel de desarrollo económico de los municipios gaditanos ha estado influido fundamentalmente por el crecimiento de la productividad y por el crecimiento del sector industrial, con una destacada productividad respecto al resto de los sectores productivos.

g) Teniendo en cuenta la influencia ejercida por la productividad en el nivel de desarrollo económico de los municipios gaditanos, creemos necesario seguir trabajando en esta línea, analizando la influencia de factores como el capital humano, las infraestructuras y la innovación y el cambio tecnológico, entre otros, lo que permitiría un estudio más detallado de cómo estos factores han afectado el nivel de prosperidad económica territorial, información que creemos de sumo interés para la planificación de 
las acciones necesarias tendentes a corregir las disparidades económicas territoriales en el conjunto de los municipios de la provincia de Cádiz.

\section{ANEXO I}

\section{Municipios de la provincia de Cádiz}

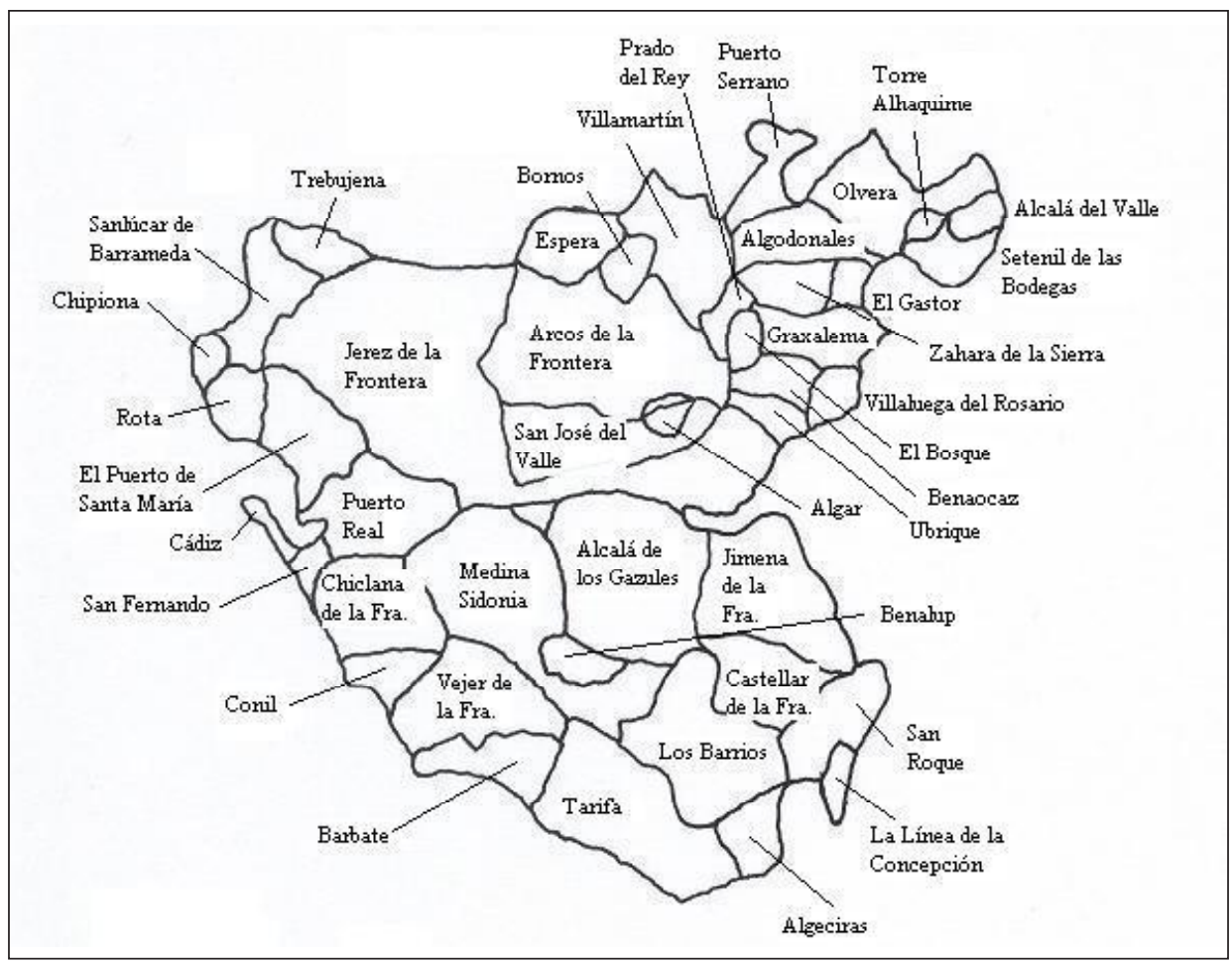




\section{Bibliografía}

Almeida García, F.; Granados Cabezas, V. (1999). "Indicador de calidad de vida y su especialización territorial en Andalucía”. Boletín Económico de Andalucía, Núm. 26, Consejería de Economía y Hacienda, Junta de Andalucía, pp. 29-42.

Alonso, J.; Freire-Seren, M.J. (2002). "Infraestructuras sociales: su efecto sobre el crecimiento de la productividad de las CC.AA. españolas". Revista de Estudios Regionales, Núm. 64, pp. 167-186.

Barro, R.J.; Sala-I-Martín, X. (1992). "Convergence”. Journal of Political Economy, vol. 100, Núm. 21, pp. 223-251.

Borts, G.H.; Stein, J.L. (1964). Economic growth in a free market. Columbia University Press, New York.

Bueno Lastra, J. (1990). Los desequilibrios regionales. Teoría y realidad española. Ed. Pirámide, Madrid.

Cancelo de la Torre, J.R.; Uriz Tomé, P. (1994). Una metodología general para la elaboración de índices complejos de dotación de infraestructuras". Revista de Estudios Regionales, Núm. 40, pp. 167-188.

Cuadrado Roura, J.R. (Dir.) et al. (1983). Estudio económico de la provincia de Cádiz. Análisis descriptivo y diagnóstico de la situación actual. Diputación de Cádiz, Cádiz.

Cuadrado Roura, J.R. (Dir.); Mancha Navarro, T.; Garrido Yserte, R. (1998). Convergencia regional en España: Hechos, tendencias y perspectivas. Ed. Fundación Argentaria-Visor, Madrid.

Cuadrado Roura, J.R.; Garrido Yserte, R.; Mancha Navarro, T. (1999). "Disparidades regionales y convergencia en España. 1980-1995". Revista de Estudios Regionales, Núm. 55, pp. 109-137. 
Delgado Cabeza, M. (2001). "El funcionamiento de la economía andaluza”, en Cano García, G. (Dir.), Conocer Andalucía. Gran enciclopedia andaluza del siglo XXI, Ed. Tartessos, Sevilla, pp. 12-43.

Delgado Cabeza, M.; González de Molina, M. (2001). "La agricultura andaluza”, en Cano García, G. (Dir.), Conocer Andalucía. Gran enciclopedia andaluza del siglo XXI, Ed. Tartessos, Sevilla, pp. 45-81.

Draper, M.; Herce, J.A. (1994). "Infraestructuras y crecimiento: un panorama”. Revista de Economía Aplicada, Núm. 6, vol. II, pp. 129-168.

Ezcurra, R.; Pascual, P.; Rapún, M. (2003). "Movilidad y desigualdad regional en la Unión Europea”. Investigaciones Regionales, Núm. 2, pp. 5-93.

Fundación BBV (1999). Renta Nacional de España y su distribución provincial. Serie homogénea. Años 1955 a 1993 y avances 1994 a 1997. 3 tomos. Fundación BBV, Bilbao.

Fundación BBVA (2000). Renta Nacional de España y su distribución provincial. Año 1995 y avances 1996-1999. Fundación BBVA, Bilbao.

García Greciano, B.; Raynond Bara, J.L.; Villaverde Castro, J. (1995). "La convergencia de las provincias españolas”. Papeles de Economía Española, Núm. 64, pp. 38-53.

García Greciano, B.; Raymond Bara, J.L. (1999): "Las disparidades regionales y la hipótesis de convergencia: una revisión”. Papeles de Economía Española, Núm. 80, pp. 2-18.

Goerlich, F.J.; Mas, M. (1999). “Medición de la desigualdad: contribución a una base de datos regional”. Documento de trabajo, septiembre. Instituto Valenciano de Investigaciones Económicas, Valencia.

Hirschman, A.O. (1958). The strategy of economic development. Yale University Press, New Haven (traducción en español: La estrategia del desarrollo económico, Fondo de Cultura Económica, México, 1981). 
Instituto de Estadística de Andalucía (IEA). Sistema de Información Multiterritorial de Andalucía (SIMA), Consejería de Economía y Hacienda de la Junta de Andalucía (http://www.juntadeandalucia.es/institutodeestadistica/).

Instituto Nacional de Estadística (INE). Contabilidad Regional de España. Base 1995. Base de datos TEMPUS (http://www.ine.es).

Kaldor, N. (1970). "The case for regional policies". Scottish Journal of Political Economy, Núm. 17, pp. 347-447.

Lucas, R.E. (1988). "On the mechanics of development planning”. Journal of Monetary Economics, vol. XXII, pp. 3-42.

Martín Rodríguez, M. (1998). "La economía de las regiones españolas en el largo y muy largo plazo”, en Mella Márquez, J.M., Economía y Política Regional en España ante la Europa del siglo XXI, Ed. Akal Textos, Madrid, pp. 129-146.

Peña Sánchez, A.R. (2004). "Las disparidades económicas intrarregionales en Andalucía”. Tesis Doctoral. Universidad de Cádiz. Publicada en EUMED en 2006 (http://www.eumed.net/tesis/-2006/arps/).

Peña Sánchez, A.R. (2006). "Las disparidades económicas intermunicipales en la provincia de Cádiz: un análisis desde la óptica de la convergencia”. Documento de trabajo, Serie Economía E2006/13, Fundación Centro de Estudios Andaluces. Consejería de la Presidencia, Junta de Andalucía, Sevilla.

Peña Sánchez, A.R. (2007). "La concentración de la producción en Andalucía en la década de los noventa: configuración del mapa de densidad productiva”. Revista de Economía, Núm. 68 y 69, vol. I, primer y segundo semestre, Facultad de Economía de la Universidad Autónoma de Yucatán (México). 
Peña sánchez, A.R.; Rodríguez García, J. (1996a). "La concentración de la tierra en Andalucía en la década de los 80: una aproximación cuantitativa”. Revista de Estudios Regionales, Núm. 46, pp. 211-239.

Peña Sánchez, A.R.; Rodríguez García, J. (1996b). "Cambios estructurales en el sector agrario gaditano en la década de los 80". Anales de la Universidad de Cádiz, Núm. XI, Servicio de Publicaciones de la Universidad de Cádiz, pp. 355-366.

Richardson, H.W. (1975). Elementos de economía regional. Ed. Alianza Editorial, Madrid.

RICHARDSON, H.W. (1977): Teoría del crecimiento regional. Ed. Pirámide, Madrid.

Romer, P.M. (1986). "Increasing returns and long-run growth". Journal of Political Economy, vol. XCIV, pp. 1002-1037.

Rosende, F. (2000). "Teoría del crecimiento económico: un debate inconcluso”. Estudios de Economía, vol. 27, pp. 95-122.

Rupansingha, A.; Goetz, S.J.; Freshwater, D. (2002). "Social and institucional factor as determinants of economic growth: Evidence from the Unites States counties". Papers in Regional Science, vol. 81, Núm. 2, pp. 139-155.

Sala-I-Martín, X. (1990). On Growth and States. Ph. D. dissertation, Harvard University.

Sala-I-Martín, X. (1994). "La riqueza de las regiones. Evidencia y teorías sobre crecimiento regional y convergencia”. Moneda y Crédito, Núm. 198, pp. 13-54.

Sala-I-Martín, X. (1996): "Regional cohesion. Evidence and theories of regional growth and convergence". European Economic Review, vol. 40, pp. 1325-1352. 
Sala-I-Martín, X. (1999). Apuntes de Crecimiento Económico. Ed Antoni Bosch, Barcelona.

Salas, R. (1999). "Convergencia, movilidad y redistribución interregional en España: 1981-1996”. Papeles de Economía Española, Núm. 80, pp. 1928.

Solow, R.M. (1956). "A contribution to the Theory of Economic Growth". Quarterly Journal of Economic, vol. 70, pp. 65-94.

Villaverde Castro, J. (1999). Diferencias regionales en España y Unión Monetaria Europea. Ed. Pirámide, Madrid. 